\title{
Concentrated solar power plants: Review and design methodology
}

\author{
H.L. Zhang ${ }^{\text {a,* }}$, J. Baeyens ${ }^{b}$, J. Degrève ${ }^{a}$, G. Cacères ${ }^{c}$ \\ a Department of Chemical Engineering, Chemical and Biochemical Process Technology and Control Section, Katholieke Universiteit Leuven, Heverlee 3001, Belgium \\ ${ }^{\mathrm{b}}$ School of Engineering, University of Warwick, Coventry, UK \\ c Facultad de Ingeniería y Ciencias, Universidad Adolfo Ibáñez, Santiago, Chile
}

\section{A R T I C L E I N F O}

\section{Article history:}

Received 17 November 2012

Received in revised form

24 January 2013

Accepted 26 January 2013

Available online 15 March 2013

Keywords:

Concentrated solar power plants

Design methodology

Solar towers

Hourly beam irradiation

Plant simulation

\begin{abstract}
A B S T R A C T
Concentrated solar power plants (CSPs) are gaining increasing interest, mostly as parabolic trough collectors (PTC) or solar tower collectors (STC). Notwithstanding CSP benefits, the daily and monthly variation of the solar irradiation flux is a main drawback. Despite the approximate match between hours of the day where solar radiation and energy demand peak, CSPs experience short term variations on cloudy days and cannot provide energy during night hours unless incorporating thermal energy storage (TES) and/or backup systems (BS) to operate continuously. To determine the optimum design and operation of the CSP throughout the year, whilst defining the required TES and/or BS, an accurate estimation of the daily solar irradiation is needed. Local solar irradiation data are mostly only available as monthly averages, and a predictive conversion into hourly data and direct irradiation is needed to provide a more accurate input into the CSP design. The paper (i) briefly reviews CSP technologies and STC advantages; (ii) presents a methodology to predict hourly beam (direct) irradiation from available monthly averages, based upon combined previous literature findings and available meteorological data; (iii) illustrates predictions for different selected STC locations; and finally (iv) describes the use of the predictions in simulating the required plant configuration of an optimum STC.

The methodology and results demonstrate the potential of CSPs in general, whilst also defining the design background of STC plants.
\end{abstract}

\section{Contents}

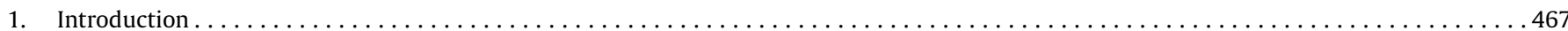

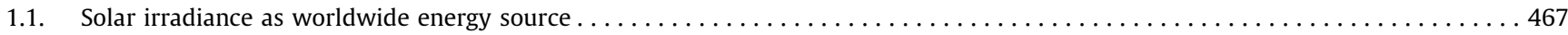

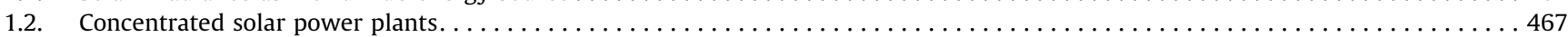

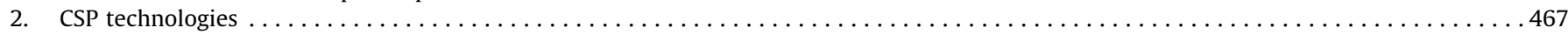

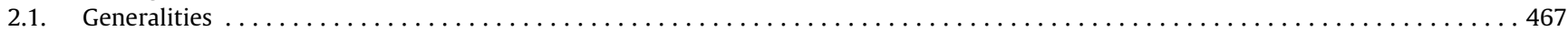

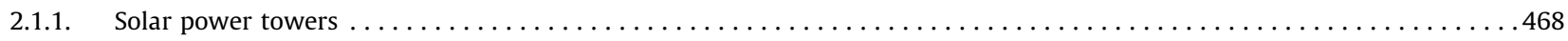

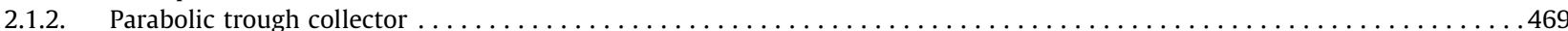

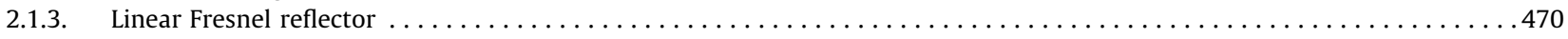

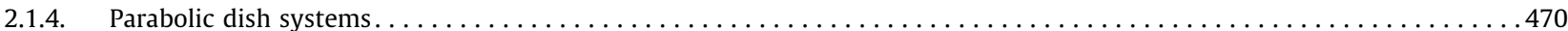

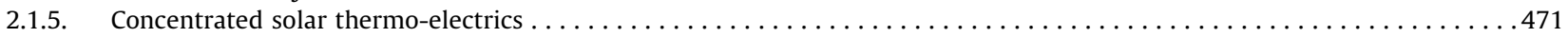

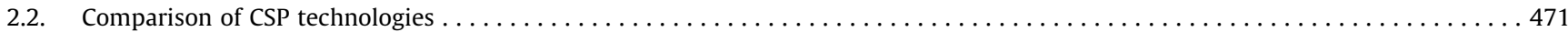

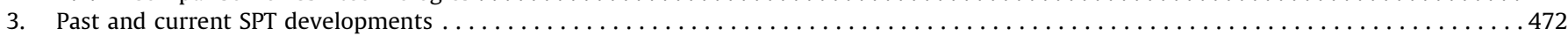

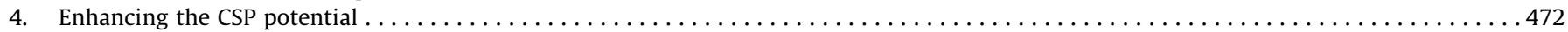

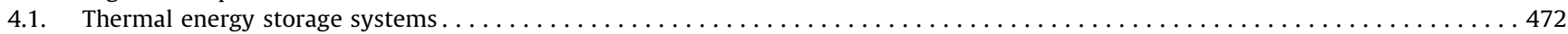

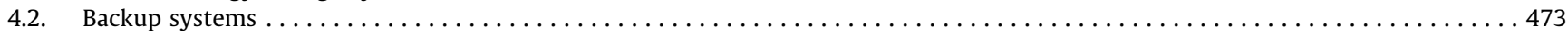

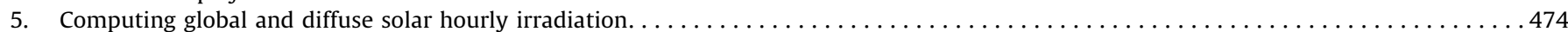

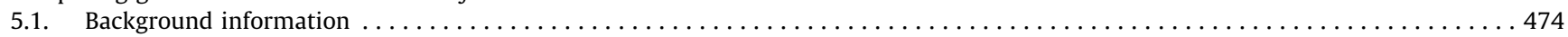

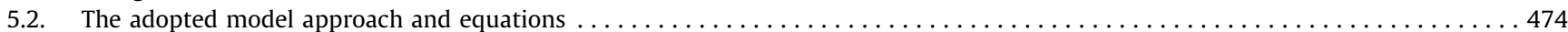

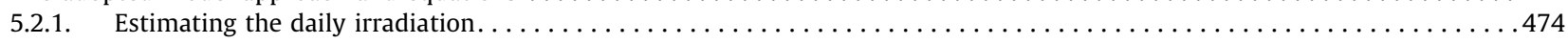

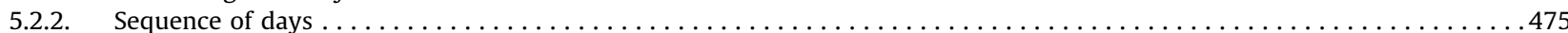

\footnotetext{
* Corresponding author. Tel.: +32 16 322695; fax: +32 16322991 .

E-mail address: Zhanghl.lily@gmail.com (H.L. Zhang).
} 


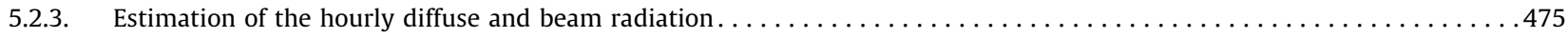

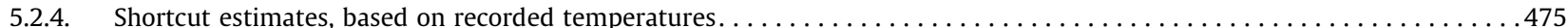

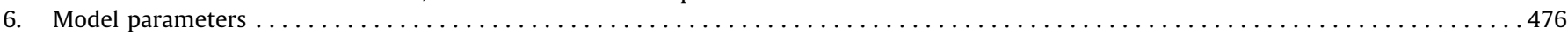

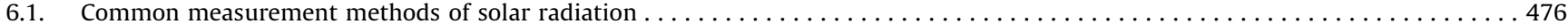

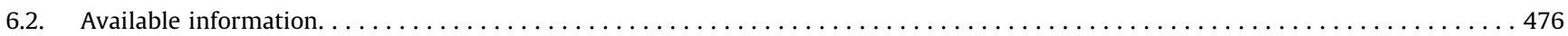

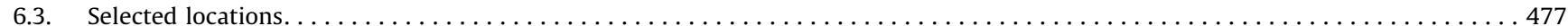

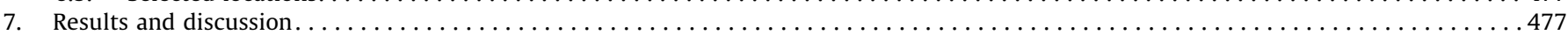

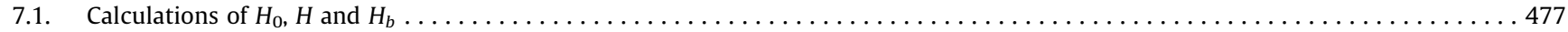

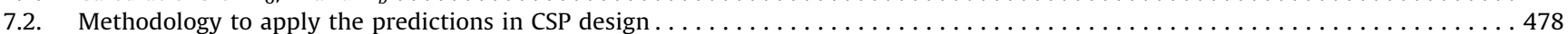

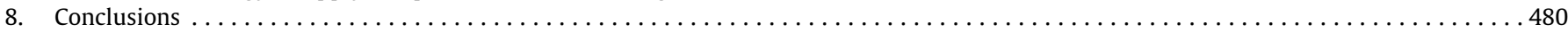

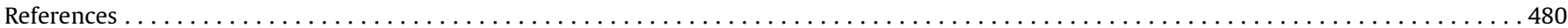

\section{Introduction}

\subsection{Solar irradiance as worldwide energy source}

More energy from the sunlight strikes the earth in $1 \mathrm{~h}$ than all of the energy consumed by humans in an entire year. In fact, solar energy dwarfs all other renewable and fossil-based energy resources combined.

We need energy - electrical or thermal - but in most cases where and when it is not available. Low cost, fossil-based electricity has always served as a significant cost competitor for electrical power generation. To provide a durable and widespread primary energy source, solar energy must be captured, stored and used in a cost-effective fashion.

Solar energy is of unsteady nature, both within the day (daynight, clouds) and within the year (winter-summer). The capture and storage of solar energy is critical if a significant portion of the total energy demand needs to be provided by solar energy.

Fig. 1 illustrates the world solar energy map. Most of the countries, except those above latitude $45^{\circ} \mathrm{N}$ or below latitude $45^{\circ} \mathrm{S}$, are subject to an annual average irradiation flux in excess of $1.6 \mathrm{MW} \mathrm{h} / \mathrm{m}^{2}$, with peaks of solar energy recorded in some "hot" spots of the Globe, e.g., the Mojave Desert (USA), the Sahara and Kalahari Deserts (Africa), the Middle East, the Chilean Atacama Desert and North-western Australia.

\subsection{Concentrated solar power plants}

Concentrated solar power plants are gaining increasing interest, mostly by using the parabolic trough collector system (PTC), although solar power towers (SPT) progressively occupy a significant market position due to their advantages in terms of higher efficiency, lower operating costs and good scale-up potential. The large-scale STC technology was successfully demonstrated by Torresol in the Spanish Gemasolar project on a 19.9 $\mathrm{MW}_{\mathrm{el}}$-scale [2].

Notwithstanding CSP benefits, the varying solar radiation flux throughout the day and throughout the year remains a main problem for all CSP technologies: despite the close match between hours of the day in which energy demand peaks and solar irradiation is available, conventional CSP technologies experience short term variations on cloudy days and cannot provide energy during night hours. In order to improve the overall yield in comparison with conventional systems, the CSP process can be enhanced by the incorporation of two technologies, i.e., thermal energy storage (TES) and backup systems (BS). Both systems facilitate a successful continuous and year round operation, thus providing a stable energy supply in response to electricity grid demands. To determine the optimum design and operation of the CSP throughout the year, whilst additionally defining the capacity of TES and required BS, an accurate estimation of the daily solar irradiation is needed. Solar irradiation data for worldwide locations are mostly only available as monthly averages, and a predictive conversion into hourly data and direct irradiation is needed to provide a more accurate input into the CSP design. Considering that a CSP plant will only accept direct normal irradiance (DNI) in order to operate, a clear day model is required for calculating the suitable irradiation data.

The procedure, outlined in the present paper, combines previous theoretical and experimental findings into a general method of calculating the hourly beam irradiation flux. The basis was previously outlined by Duffie and Beckmann [3], and uses the Liu and Jordan [4] generalized distributions of cloudy and clear days, later modified by Bendt et al. [5], then by Stuart and Hollands [6] and finally by Knight et al. [7].

The present paper has therefore the following specific objectives:

- review the CSP technologies and discuss solar power tower advantages compared to the other technologies;

- estimate the hourly beam irradiation flux from available monthly mean global irradiation data for selected locations, and compare the results obtained of monthly data with calculations from the temperatures recorded at the locations;

- select an appropriate plant configuration, and present design preliminary recommendations using predicted hourly beam irradiation data.

In general, the study will demonstrate the global potential of implementing the SPT technology, and will help to determine the most suitable locations for the installation of SPT plants.

\section{CSP technologies}

\subsection{Generalities}

Concentrated solar power (CSP) is an electricity generation technology that uses heat provided by solar irradiation concentrated on a small area. Using mirrors, sunlight is reflected to a receiver where heat is collected by a thermal energy carrier (primary circuit), and subsequently used directly (in the case of water/steam) or via a secondary circuit to power a turbine and generate electricity. CSP is particularly promising in regions with high DNI. According to the available technology roadmap [8], CSP can be a competitive source of bulk power in peak and intermediate loads in the sunniest regions by 2020 , and of base load power by 2025 to 2030 .

At present, there are four available CSP technologies (Fig. 2): parabolic trough collector (PTC), solar power tower (SPT), linear Fresnel reflector (LFR) and parabolic dish systems (PDS). Additionally, a recent technology called concentrated solar thermo- 


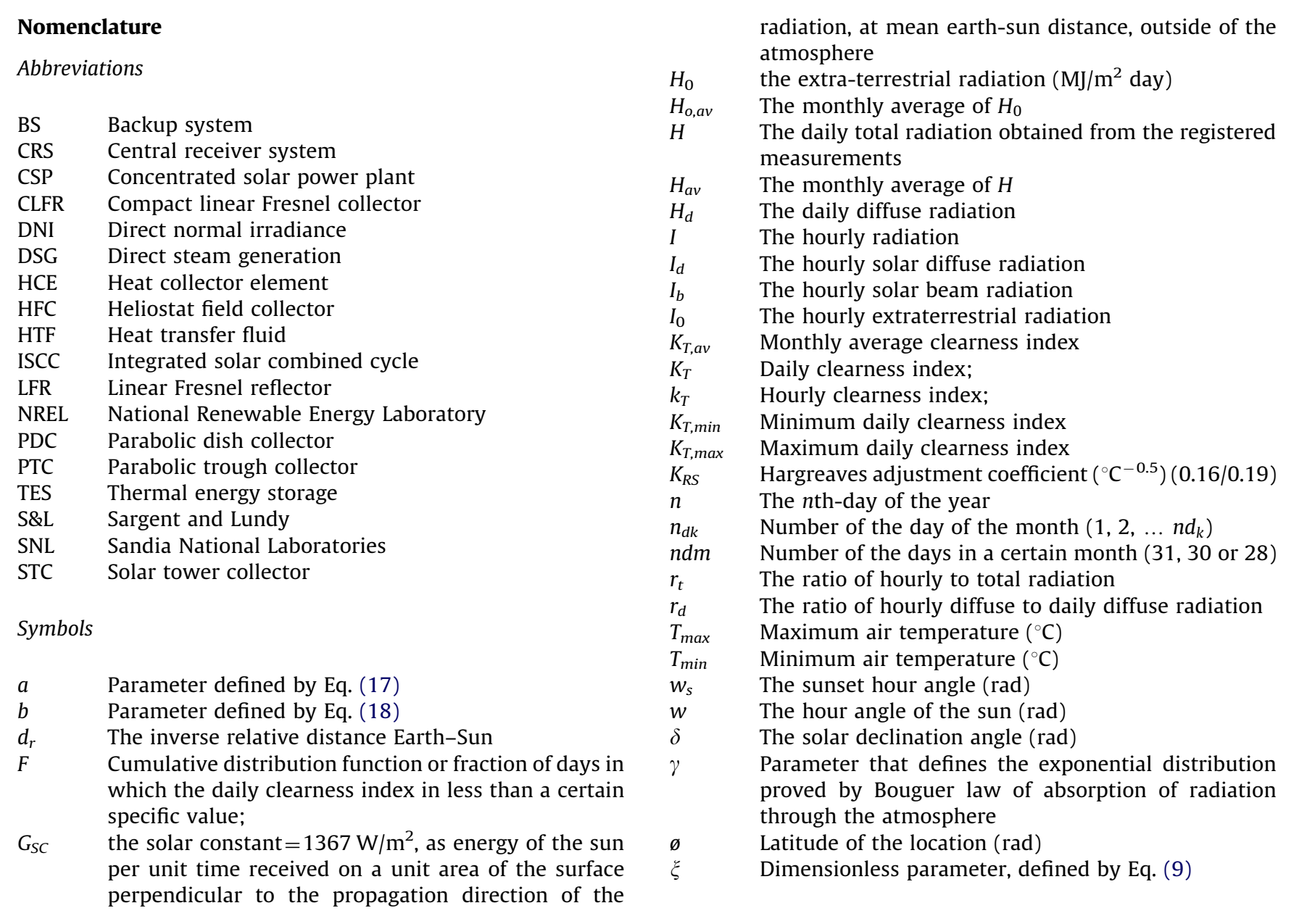

electrics is described. These CSP technologies are currently in medium to large-scale operation and mostly located in Spain and in the USA as shown in Fig. 3. Although PTC technology is the most mature CSP design, solar tower technology occupies the second place and is of increasing importance as a result of its advantages, as discussed further.

\subsubsection{Solar power towers}

Solar power towers (SPT), also known as central receiver systems (CRS), use a heliostat field collector (HFC), i.e., a field of sun tracking reflectors, called heliostats, that reflect and concentrate the sunrays onto a central receiver placed in the top of a fixed tower $[2,9]$. Heliostats are flat or slightly concave mirrors

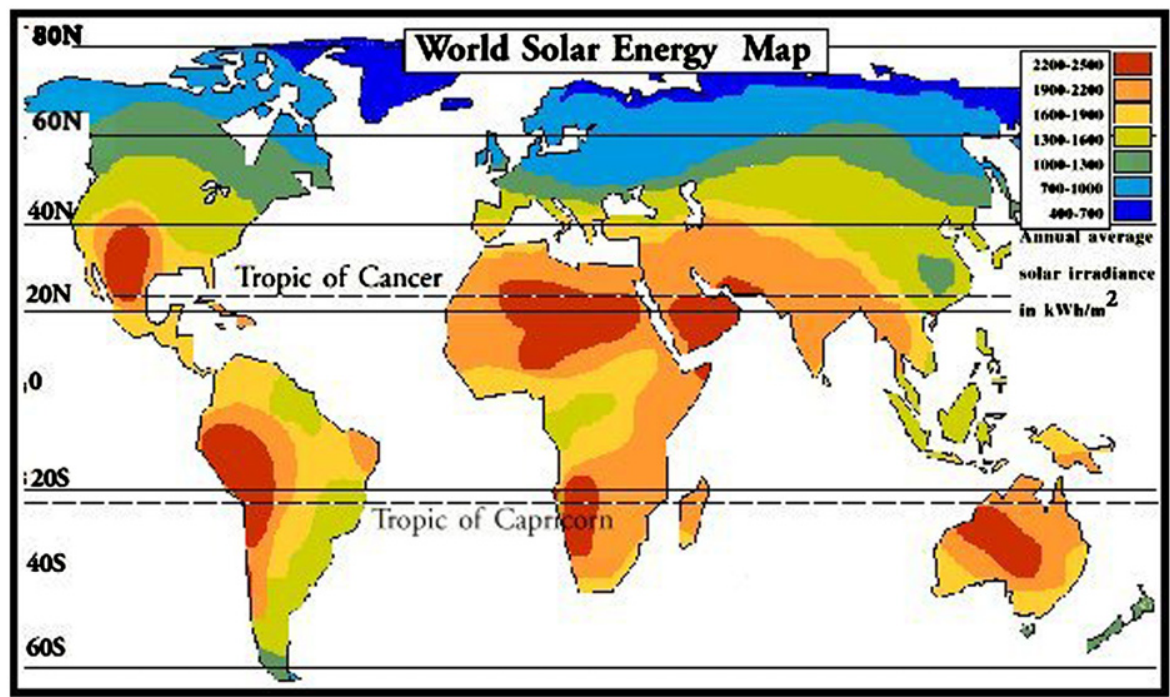

Fig. 1. World solar energy map [1]. 

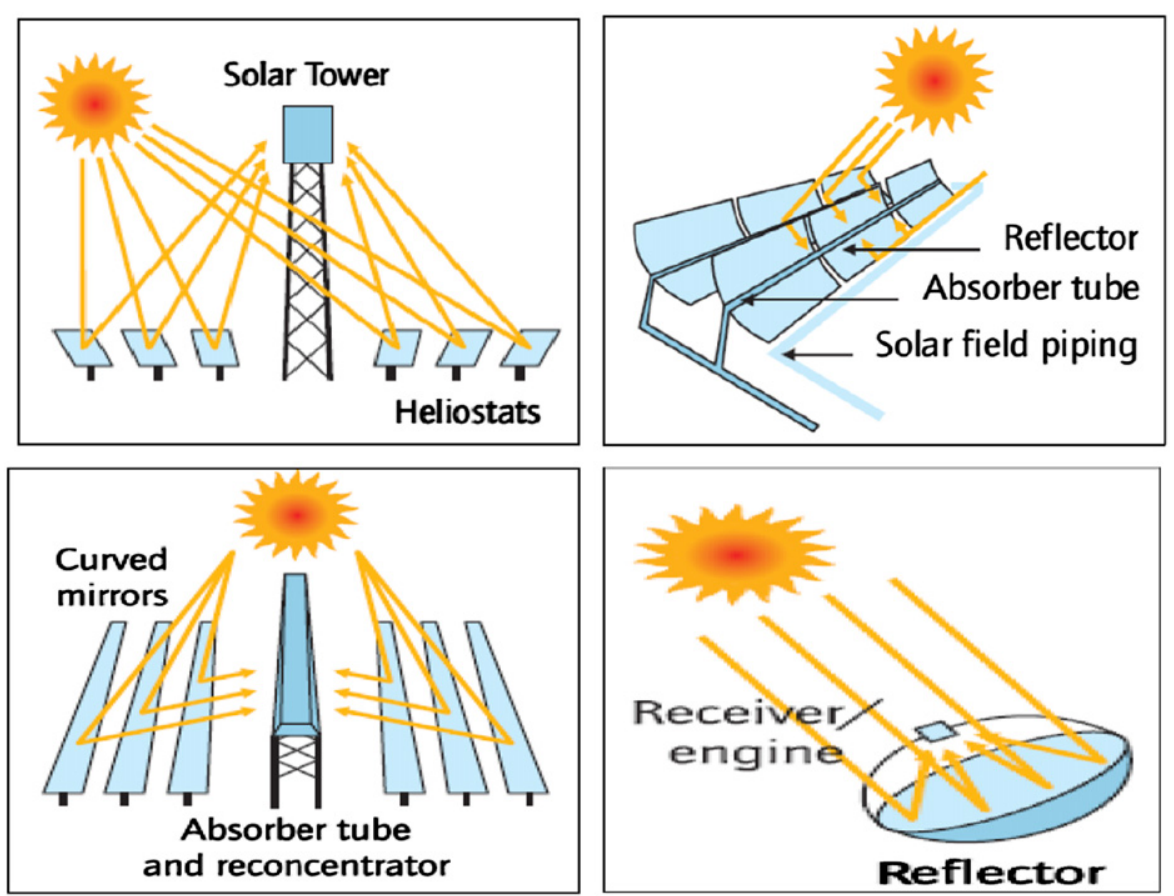

Fig. 2. Currently available CSP Technologies:(a) STP; (b)PTC; (c) LFR; (d) PDC [8].
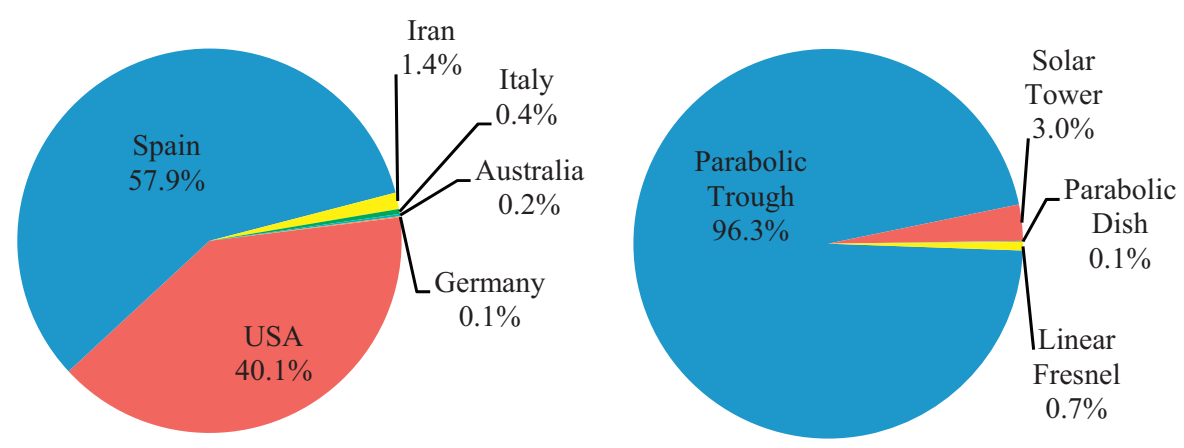

Fig. 3. Installed operational CSP power (March 2011), by country and by technology [10].

that follow the sun in a two axis tracking. In the central receiver, heat is absorbed by a heat transfer fluid (HTF), which then transfers heat to heat exchangers that power a steam Rankine power cycle. Some commercial tower plants now in operation use direct steam generation (DSG), others use different fluids, including molten salts as HTF and storage medium [9]. The concentrating power of the tower concept achieves very high temperatures, thereby increasing the efficiency at which heat is converted into electricity and reducing the cost of thermal storage. In addition, the concept is highly flexible, where designers can choose from a wide variety of heliostats, receivers and transfer fluids. Some plants can have several towers to feed one power block.

\subsubsection{Parabolic trough collector}

A parabolic trough collector (PTC) plant consists of a group of reflectors (usually silvered acrylic) that are curved in one dimension in a parabolic shape to focus sunrays onto an absorber tube that is mounted in the focal line of the parabola. The reflectors and the absorber tubes move in tandem with the sun as it daily crosses the sky, from sunrise to sunset $[9,10]$. The group of parallel connected reflectors is called the solar field.

Typically, thermal fluids are used as primary HTF, thereafter powering a secondary steam circuit and Rankine power cycle.

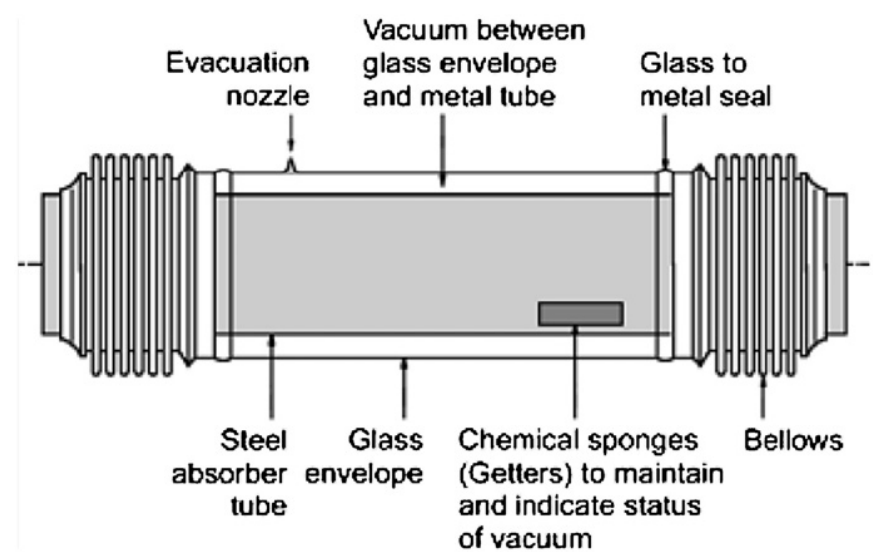

Fig. 4. Absorber element of a parabolic trough collector [9].

Other configurations use molten salts as HTF and others use a direct steam generation (DSG) system.

The absorber tube (Fig. 4), also called heat collector element (HCE), is a metal tube and a glass envelope covering it, with either air or vacuum between these two to reduce convective heat losses and allow for thermal expansion. The metal tube is coated with a 
selective material that has high solar irradiation absorbance and low thermal remittance. The glass-metal seal is crucial in reducing heat losses.

\subsubsection{Linear Fresnel reflector}

Linear Fresnel reflectors (LFR) approximate the parabolic shape of the trough systems by using long rows of flat or slightly curved mirrors to reflect the sunrays onto a downward facing linear receiver. The receiver is a fixed structure mounted over a tower above and along the linear reflectors. The reflectors are mirrors that can follow the sun on a single or dual axis regime. The main advantage of LFR systems is that their simple design of flexibly bent mirrors and fixed receivers requires lower investment costs and facilitates direct steam generation, thereby eliminating the need of heat transfer fluids and heat exchangers. LFR plants are however less efficient than PTC and SPT in converting solar energy to electricity. It is moreover more difficult to incorporate storage capacity into their design.

A more recent design, known as compact linear Fresnel reflectors (CLFR), uses two parallel receivers for each row of mirrors and thus needs less land than parabolic troughs to produce a given output [11].The first of the currently operating LFR plants, Puerto Errado 1 plant (PE 1), was constructed in Germany in March 2009, with a capacity of 1.4 MW. The success of this plant motivated the design of PE 2, a $30 \mathrm{MW}$ plant to be constructed in Spain. A 5 MW plant has recently been constructed in California, USA.

\subsubsection{Parabolic dish systems}

Parabolic dish collectors (PDC), concentrate the sunrays at a focal point supported above the center of the dish. The entire system tracks the sun, with the dish and receiver moving in tandem. This design eliminates the need for a HTF and for cooling water. PDCs offer the highest transformation efficiency of any CSP system. PDCs are expensive and have a low compatibility with respect of thermal storage and hybridization [11]. Promoters claim that mass production will allow dishes to compete with larger solar thermal systems [11]. Each parabolic dish has a low power capacity (typically tens of $\mathrm{kW}$ or smaller), and each dish produces electricity independently, which means that hundreds

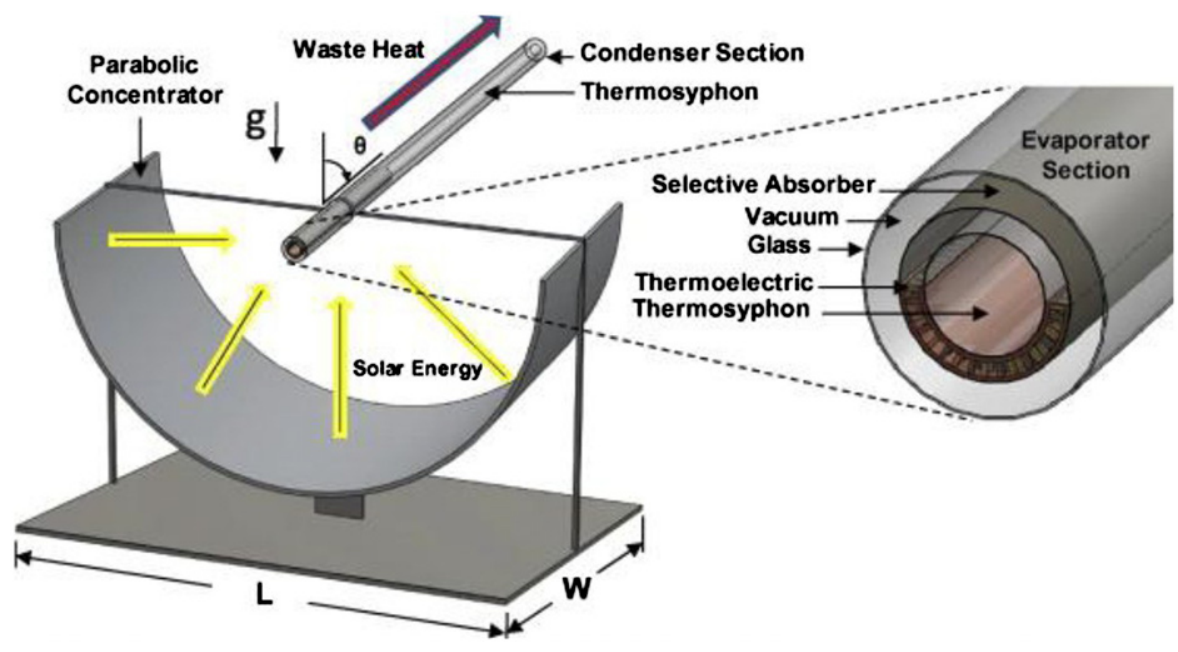

Fig. 5. Concentrated solar thermo-electric technology[11].

Table 1

Comparison between leading CSP technologies $[8,11,13]$.

\begin{tabular}{|c|c|c|c|c|c|c|c|}
\hline & Relative cost & Land occupancy & $\begin{array}{l}\text { Cooling water } \\
(\mathrm{L} / \mathrm{MW} \mathrm{h})\end{array}$ & $\begin{array}{l}\text { Thermo-dynamic } \\
\text { efficiency }\end{array}$ & $\begin{array}{l}\text { Operating } \\
\mathrm{T} \text { range }\left({ }^{\circ} \mathrm{C}\right)\end{array}$ & $\begin{array}{l}\text { Solar concentration } \\
\text { ratio }\end{array}$ & Outlook for improvements \\
\hline PTC & Low & Large & 3,000 or dry & Low & $20-400$ & $15-45$ & Limited \\
\hline LFR & Very low & Medium & 3,000 or dry & Low & $50-300$ & $10-40$ & Significant \\
\hline SPT & High & Medium & 1,500 or dry & High & $300-565$ & $150-1500$ & Very significant \\
\hline PDC & Very high & Small & None & High & $120-1500$ & $100-1000$ & $\begin{array}{l}\text { High potential through } \\
\text { mass production }\end{array}$ \\
\hline
\end{tabular}

Table 2

Comparison for $50 \mathrm{MW}_{\mathrm{el}}$ CSP plants with TES.

\begin{tabular}{|c|c|c|c|}
\hline Parameters & $\begin{array}{l}\text { PTC with oil, without } \\
\text { storage and back-up }\end{array}$ & $\begin{array}{l}\text { SPT with steam, without } \\
\text { storage and back-up }\end{array}$ & $\begin{array}{l}\text { SPT with molten salt, TES storage } \\
\text { and back-up system }\end{array}$ \\
\hline Mean gross efficiency (as \% of direct radiation) & 15.4 & 14.2 & 18.1 \\
\hline Mean net efficiency (\%) & 14 & 13.6 & 14 \\
\hline Specific power generation ( $\mathrm{kW} \mathrm{h} / \mathrm{m}^{2}$-year) & 308 & 258 & 375 \\
\hline Capacity factor (\%) & $23-50$ & 24 & Up to 75 \\
\hline Unitary investment $\left(€ / \mathrm{kW} \mathrm{h}_{\mathrm{el}}\right)$ & 1.54 & 1.43 & 1.29 \\
\hline Levelized electricity cost $\left(€ / \mathrm{kW} \mathrm{h}_{\mathrm{el}}\right)$ & $0.16-0.19$ & $0.17-0.23$ & $0.14-0.17$ \\
\hline
\end{tabular}


or thousands of them are required to install a large scale plant like built with other CSP technologies [11].

Maricopa Solar Project is the only operational PDC plant, with a net capacity of $1.5 \mathrm{MW}$. The plant began operation on January 2010 and is located in Arizona, USA.

\subsubsection{Concentrated solar thermo-electrics}

As well as with photovoltaic systems, direct conversion of solar energy into electricity can also be achieved with concentrated solar thermo-electric (CST) technology. Solar thermoelectric devices can convert solar thermal energy, with its induced temperature gradient, into electricity. They can also be modified to be used as a cooling or heating technology [11]. Recently, CSP technologies have been combined with thermo-electrics in order to achieve higher efficiencies [11]. A concentrated solar thermoelectric power generator typically consists of a solar thermal collector and a thermo-electric generator (Fig. 5). Heat is absorbed by the thermal collector, then concentrated and conducted to the thermo-electric generator, where the thermal resistance of the generator creates a temperature difference between the absorber plate and the fluid, which is proportional to the heat flux. The current cost of thermo-electric materials hampers the widespread use of CSTs.

\subsection{Comparison of CSP technologies}

Within the commercial CSP technologies, parabolic trough collector (PTC) plants are the most developed of all commercially operating plants [12]. Table 1 compares the technologies on the basis of different parameters.

In terms of cost related to plant development, SPT and PDC systems are currently more expensive, although future

Table 3

PS20, Sierra sun tower and Gemasolar technical parameters [19].

\begin{tabular}{llll}
\hline Characteristics & PS 20 & Sierra sun tower & Gemasolar \\
\hline Turbine net capacity & $20 \mathrm{MW}_{\mathrm{el}}$ & $5 \mathrm{MW}_{\mathrm{el}}$ & $19.9 \mathrm{MW}_{\mathrm{el}}$ \\
Solar field area & $150,000 \mathrm{~m}^{2}$ & $27,670 \mathrm{~m}^{2}$ & $304,750 \mathrm{~m}^{2}$ \\
Number of heliostats & 1,255 & 24,360 & 2,650 \\
Heat transfer fluid & Water & Water & Molten salt \\
Receiver outlet temperature & $2,550-300{ }^{\circ} \mathrm{C}$ & $440{ }^{\circ} \mathrm{C}$ & $565{ }^{\circ} \mathrm{C}$ \\
Backup fuel & Natural gas & Natural gas & Natural gas \\
Storage capacity & $1 \mathrm{~h}$ & (No storage) & $\begin{array}{l}15 \mathrm{~h} \\
\text { (molten salt) }\end{array}$ \\
Capacity factor & Approx. 27\% & Approx. 30\% & $70-75 \%$ \\
\hline
\end{tabular}

developments and improvements [13] will alter levelized energy cost projections, as presented by Sandia National Laboratories (SNL) and by Sargent \& Lundy Consulting Group (S\&L): SPT will be the cheaper CSP technology in 2020.

In terms of land occupancy, considering the latest improvements in CSP technologies, SPT and LFR require less land than PTC to produce a given output. Additionally, PDC has the smallest land requirement among CSP technologies $[8,12]$.

Water requirements are of high importance for those locations with water scarcity, e.g., in most of the deserts. As in other thermal power generation plants, CSP requires water for cooling and condensing processes, where requirements are relatively high: about $3000 \mathrm{~L} / \mathrm{MW}$ h for PTC and LFR plants (similar to a nuclear reactor) compared to about $2000 \mathrm{~L} / \mathrm{MW}$ h for a coal-fired power plant and only $800 \mathrm{~L} / \mathrm{MW} \mathrm{h}$ for a combined-cycle natural gas power plant. SPT plants need less water than PTC $(1500 \mathrm{~L} /$ $\mathrm{MW}$ h) [8]. Dishes are cooled by the surrounding air, so they do not require cooling water. Dry cooling (with air) is an effective alternative as proven by the plants under construction in North Africa [8]. However, it is more costly and reduces efficiencies. Dry cooling systems installed on PTC plants located in hot deserts, reduce annual electricity production by $7 \%$ and increase the cost of the produced electricity by about $10 \%$ [8]. However, the efficiency reduction caused by dry cooling is lower for SPT than for PTC. The installation of hybrid wet and dry cooling systems reduces water consumption while minimizing the performance penalty. As water cooling is more effective, operators of hybrid systems tend to use only dry cooling in the winter when cooling needs are lower, then switch to combined wet and dry cooling during the summer.

A higher concentrating ratio of the sun enables the possibility to reach higher working temperatures and better thermodynamic efficiencies. On SPT plants, the large amount of irradiation focused on a single receiver $\left(200-1000 \mathrm{~kW} / \mathrm{m}^{2}\right)$ minimizes heat losses, simplifies heat transport and reduces costs [13].

In terms of technology outlooks, SPT shows promising advances, with novel HTF being developed and achieving higher temperatures to improve the power cycle efficiencies. Moreover, higher efficiencies reduce the cooling water consumption, and higher temperatures can considerably reduce storage costs.

A tentative comparison of $50 \mathrm{MW}_{\mathrm{el}}$ CSP plants with TES $[13,14]$ is presented in Table 2 . The capacity factor is defined as the ratio of the actual output over a year and its potential output if the plant had been operated at full nameplate capacity. Capacity factors of CSP-plants without storage and back-up systems are always low, due to the lacking power production after sunset and before sunrise.

Table 4

Experimental solar power towers [12].

\begin{tabular}{|c|c|c|c|c|c|}
\hline Project & Country & Power & Heat transfer fluid & Storage medium & Operating since \\
\hline PSA SSPS-CRS & Spain & $0.5 \mathrm{MW}_{\mathrm{el}}$ & Liquid sodium & Sodium & 1981 \\
\hline EURELIOS & Italy & $1 \mathrm{MW}_{\mathrm{el}}$ & Steam & Nitrate salt/water & 1981 \\
\hline SUNSHINE & Japan & $1 \mathrm{MW}_{\mathrm{el}}$ & Steam & Nitrate salt/water & 1981 \\
\hline Solar One & USA & $10 \mathrm{MW}_{\mathrm{el}}$ & Steam & Oil/rock & 1982 \\
\hline PSA CESA-1 & Spain & $1 \mathrm{MW}_{\mathrm{el}}$ & Steam & Nitrate salt & 1983 \\
\hline MSEE/Cat B & USA & $1 \mathrm{MW}_{\mathrm{el}}$ & Molten nitrate & Nitrate salt & 1984 \\
\hline THEMIS & France & $2.5 \mathrm{MW}_{\mathrm{el}}$ & Hi-Tec salt & Hi-Tec salt & 1984 \\
\hline SPP-5 & Russia & $5 \mathrm{MW}_{\mathrm{el}}$ & Steam & Water/steam & 1986 \\
\hline TSA & Spain & $1 \mathrm{MW}_{\mathrm{el}}$ & Air & Ceramic & 1993 \\
\hline Solar Two & USA & $10 \mathrm{MW}_{\mathrm{el}}$ & Molten nitrate & Nitrate salt & 1996 \\
\hline Consolar & Israel & $0.5 \mathrm{MW}_{\text {th }}$ & Pressurized air & Fossil hybrid & 2001 \\
\hline Solgate & Spain & $0.3 \mathrm{MW}_{\mathrm{el}}$ & Pressurized air & Fossil hybrid & 2002 \\
\hline Eureka & Spain & $2 \mathrm{MW}_{\mathrm{el}}$ & Superheated steam & Pressurized $\mathrm{H}_{2} \mathrm{O}$ & 2009 \\
\hline Jülich & Germany & $1.5 \mathrm{MW}_{\mathrm{el}}$ & Air & Air/ceramic & 2009 \\
\hline CSIRO SolarGas & Australia & $0.5 \mathrm{MW}_{\text {th }}$ & Water/gas & - & 2005 \\
\hline CSIRO Brayton & Australia & $1 \mathrm{MW}_{\mathrm{th}}$ & Air & - & 2011 \\
\hline
\end{tabular}


A lower cost in SPT technology is mainly due to a lower thermal energy storage costs, which benefits from a larger temperature rise in the SPT compared to the PTC systems $[14,15]$. A higher annual capacity factor and efficiency in SPT is mainly possible due to the thermal storage, which enables a continuous and steady day-night output $[14,16]$.

Additionally, in SPT plants, the whole piping system is concentrated in the central area of the plant, which reduces the size of the piping system, and consequently reduces energy losses, material costs and maintenance [2,8]. In this scenario, solar towers with molten salt technology could be the best alternative to parabolic trough solar power plants. Considering all mentioned aspects, SPT has several potential advantages. For both SPT and PTC technology, abundant quality data of main specific components are known $[3,12,17,18]$, thus facilitating a more accurate analysis of the technology.

\section{Past and current SPT developments}

The early developments included the PS 10 and a slightly improved PS 20 (Planta Solar 10 and 20) [18] of respective capacities 11 and $20 \mathrm{MW}_{\mathrm{el}}$, built near Sevilla. The plant technologies involve glass-metal heliostats, a water thermal energy storage system $(1 \mathrm{~h})$, and cooling towers. A natural gas back-up is present $[18,19]$. The Sierra Sun Tower is the third commercial SPT plant in the world, and the first of the United States. It consist of two modules with towers of $55 \mathrm{~m}$ height, total net turbine capacity of $5 \mathrm{MW}_{\mathrm{el}}$ and constructed on approximately 8 ha. It began production in July 2009. Gemasolar is the fourth and newest commercial SPT plant in the world, as it began production in April 2011. It is the first commercially operating plant to apply molten salts as heat transfer fluid and storage medium $[2,19]$. It is located on 185 ha near Sevilla, Spain. The molten salt energy storage system is capable of providing $15 \mathrm{~h}$ of electricity production without sunlight, which enables the plant to provide electricity for 24 consecutive hours. Table 3 shows the main characteristics of the PS 20, Sierra Sun Tower and Gemasolar SPT.

Additional pilot-SPT plants have been built and developed around the world since 1981, as illustrated in Table 4 [12].

Commercial SPT plants are also being implemented, either in the design or in the construction phase, as illustrated in Table 5. Recently additional large-scale projects have been announced for e.g., Morocco, Chile, the USA, and the Republic of South Africa. (RSA). The RSA announced an initiative of $5000 \mathrm{MW}$ [20]. These projects are not considered in Table 5, for current lack of detailed information.

\section{Enhancing the CSP potential}

As stated before, the CSP potential can be enhanced by the incorporation of two technologies in order to improve the competitiveness towards conventional systems: Thermal energy storage (TES) and backup systems (BS). Both systems offer the possibility of a successful year round operation, providing a stable energy supply in response to electricity grid demands $[2,3]$.

\subsection{Thermal energy storage systems}

Thermal energy storage systems (TES) apply a simple principle: excess heat collected in the solar field is sent to a heat exchanger and warms the heat transfer fluid (HTF) going from the cold tank to the hot tank. When needed, the heat from the hot tank can be returned to the HTF and sent to the steam generator (Fig. 6). In the absence of storage capacity, on the sunniest hours,

Table 5

Developing solar power tower projects [19].

\begin{tabular}{|c|c|c|c|c|c|}
\hline Project & Country & Nominal power output & HTF & Storage medium & Projected to start operation \\
\hline BrightSource Coyote springs 1 & Nevada, USA & $200 \mathrm{MW}_{\mathrm{el}}$ & Water & - & July 2014 \\
\hline BrightSource Coyote springs 2 & Nevada, USA & $200 \mathrm{MW}_{\mathrm{el}}$ & Water & - & July 2015 \\
\hline BrightSource PG\&E 5 & California, USA & $200 \mathrm{MW}_{\mathrm{el}}$ & Water & - & July 2016 \\
\hline BrightSource PG\&E 6 & California, USA & $200 \mathrm{MW}_{\mathrm{el}}$ & Water & - & December 2016 \\
\hline BrightSource PG\&E 7 & California, USA & $200 \mathrm{MW}_{\mathrm{el}}$ & Water & - & July 2017 \\
\hline Crescent Dunes Solar Energy Project (Tonopah) & Nevada, USA & $110 \mathrm{MW}_{\mathrm{el}}$ & Molten salt & Molten salt & October 2013 \\
\hline Gaskell sun tower & California, USA & $245 \mathrm{MW}_{\mathrm{el}}$ & Water & - & May 2012 \\
\hline Ivanpah Solar Electric Generating Station (ISEGS) & California, USA & $370 \mathrm{MW}_{\mathrm{el}}$ & Water & - & October 2013 \\
\hline Rice Solar Energy Project (RSEP) & California, USA & $150 \mathrm{MW}_{\mathrm{el}}$ & Molten salt & Molten salt & October 2013 \\
\hline
\end{tabular}

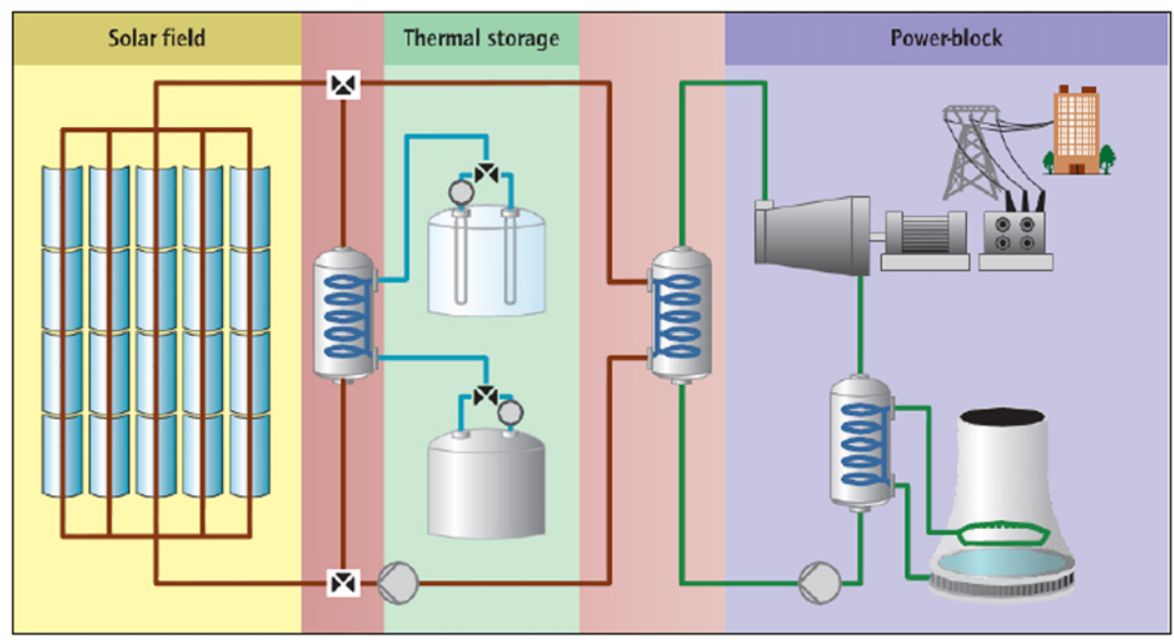

Fig. 6. Thermal energy storage system in a parabolic trough collector plant [8]. 
plant operators defocus some unneeded solar collectors to avoid overheating the HTF. Storage avoids losing the daytime surplus energy while extending the production after sunset.

Two types of thermal storage are necessary to maintain a constant supply through the year, Short and Long term energy storage. Short term thermal energy storage collects and stores surplus daytime energy for nighttime consumption. Long term thermal energy storage is less obvious, since involving storage in spring and summer for autumn and winter months. Currently, only sensible heat is stored. The significant improvement by using latent heat storage (phase change materials) or even chemical heat storage (reversible endothermic/exothermic synthesis) is in full development [21], with chemical heat being considered more suitable for long term thermal energy storage.

Thermal storage can be achieved directly or indirectly. Liquids e.g., mineral oil, synthetic oil, silicone oil, molten salts, can be used for sensible heat in direct thermal storage systems. For molten salts, the desired characteristics for sensible heat usage are high density, low vapor pressure, moderate specific heat, low chemical reactivity and low cost [21]. Indirect storage is where HTF circulates heat, collected in the absorbers, and then pumped to the thermal energy storage system. The storage material (solid material) absorbs heat from the HTF in heat exchangers, while the solid material and the HTF are in thermal contact.

The thermal storage capacity can be varied in order to meet different load requirements, and different options are possible, depending on the storage capacity included, i.e., (i) with a small storage only, if electricity is only produced when the sunshine is available; (ii) in a delayed intermediate load configuration, where solar energy is collected during daytime, but with an extended electricity production, or a production only when demand peaks; (iii) in a fully continuous mode, with a sufficiently large storage capacity to cover electricity production between sunset and sunrise (e.g., Gemasolar).

In order to select optimum sensible heat storage materials, the heat capacity plays a major role [11,21], and values are illustrated in Fig. 7.

Molten single salts tend to be expensive [11],as illustrated in Fig. 8.

The molten nitrate salt, used as HTF and storage medium, is a combination of $60 \mathrm{wt} \%$ sodium nitrate $\left(\mathrm{NaNO}_{3}\right)$ and $40 \mathrm{wt} \%$ potassium nitrate $\left(\mathrm{KNO}_{3}\right)$. It is a stable mixture and has a low vapor pressure. It can be used within a temperature range of $260{ }^{\circ} \mathrm{C}$ to $\sim 621{ }^{\circ} \mathrm{C}$. However, as the temperature decreases, it starts to crystallize at $238{ }^{\circ} \mathrm{C}$ and solidifies at $221{ }^{\circ} \mathrm{C}$ [21].

\subsection{Backup systems}

CSP plants, with or without storage, are commonly equipped with a fuel backup system (BS), that helps to regulate production and to guarantee a nearly constant generation capacity, especially in peak periods. CSP plants equipped with backup systems are called hybrid plants. Burners can provide energy to the HTF, to the storage medium, or directly to the power block. The integration of the BS can moreover reduce investments in reserve solar field and storage capacity. CSP can also be used in a hybrid mode by adding a small solar field to a fossil fuel fired power plant. These systems are called integrated solar combined cycle plants (ISCC). As the solar share is limited, such hybridization only limits fuel use. A positive aspect of solar fuel savers is their relatively low cost:

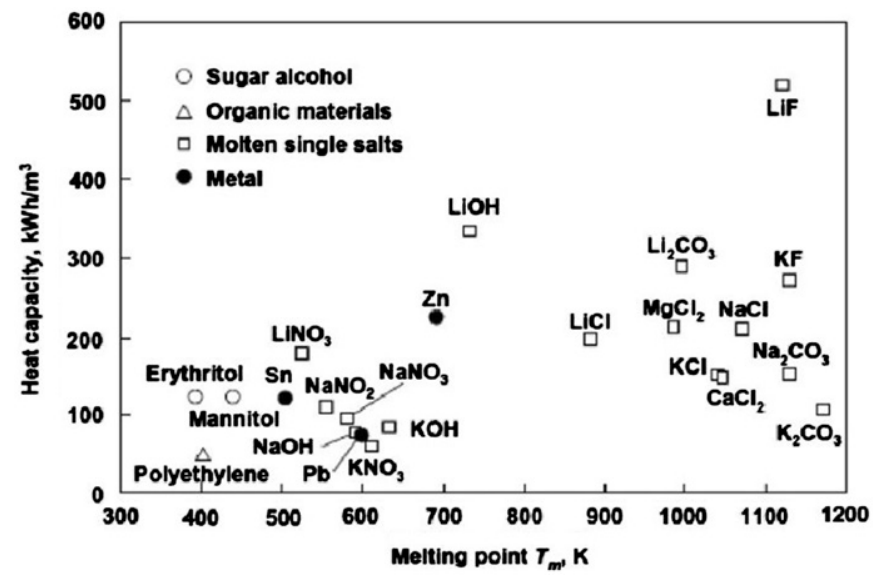

Fig. 7. Heat capacity of different storage materials, $\left(\mathrm{kW} \mathrm{h} / \mathrm{m}^{3}\right)$ versus melting points $\left({ }^{\circ} \mathrm{K}\right)[11]$

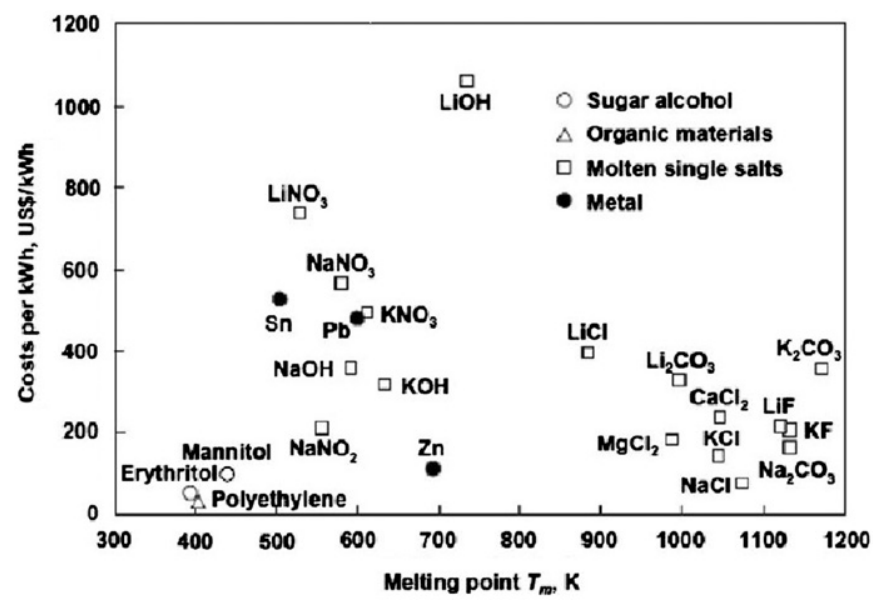

Fig. 8. Cost of different storage materials (US\$/kW h) versus melting points ( $\left.{ }^{\circ} \mathrm{K}\right)[10]$.
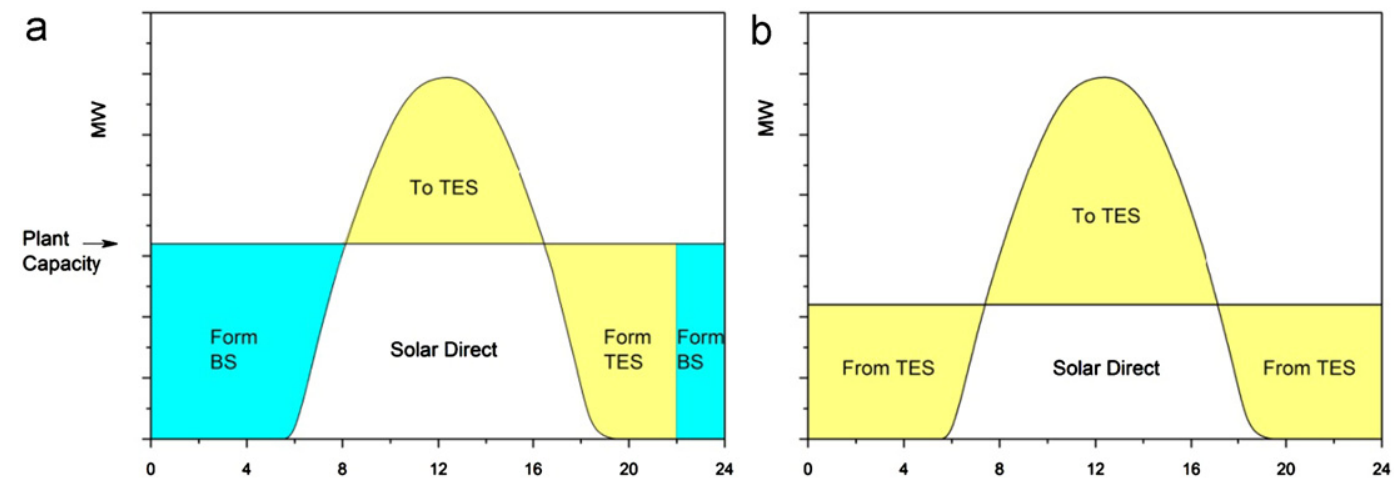

Fig. 9. Possible combination of hybridization (a) and sole TES (b) in a solar plant 
with the steam cycle and turbine already in place, only components specific to CSP require additional investment.

Fig. 9 shows a typical performance for a CSP plant enhanced with thermal energy storage system and backup system, in a constant generation at nominal capacity.

\section{Computing global and diffuse solar hourly irradiation}

\subsection{Background information}

To determine the optimum design and operation of the CSP throughout the year, whilst additionally defining the potential of TES and required BS, an accurate estimation of the daily solar irradiation is needed. Solar irradiation data for worldwide locations are mostly only available as monthly averages (see Section 6 ), and a predictive conversion into hourly data and direct irradiation is needed to provide a more accurate input into the CSP design. It is therefore necessary to apply a methodology that converts these values into hourly databases. Considering that a CSP plant will only accept direct normal irradiance (DNI) in order to operate, a clear day model is required for calculating the appropriate irradiation data.

Although numerous researchers $(<2000)$ have generated calculation procedures for obtaining synthetic data on a daily or hourly basis [7,22-32], the present paper updates and combines the essentials of these different publications into expressions of daily distributions and hourly variations for any selected location, starting from the monthly average solar irradiation value, by generating a sequence of daily and hourly solar irradiation values. Such a sequence must represent the trend of solar irradiation in a specific area, with respect to the values observed, the monthly average value and its distribution (the "good and bad" days).

The essential parameter is a dimensionless clearness index variable, defined as the ratio of the horizontal global solar irradiation and the horizontal global extra-terrestrial solar irradiation, defined as a monthly, a daily, and an hourly characteristic.

In general, the meteorological variable solar radiation is neither completely random, nor completely deterministic. Highly random for short periods of time (days, hours), it is deterministic for longer periods of time (months, years). The extra-terrestrial solar irradiation can be predicted accurately for any place and time, since the specific atmospheric conditions of a given area will determine the random characteristics of the solar irradiation at ground level.

\subsection{The adopted model approach and equations}

\subsubsection{Estimating the daily irradiation}

Before obtaining hourly data, estimations of daily irradiation must be calculated first, as shown below.

First, it is necessary to compute the monthly average clearness index for each month and location, which is defined as:

$K_{T, a v}=H_{a v} / H_{o, a v}$

Where $H_{a v}$ is the monthly average irradiation, obtained from the registered measurements, as discussed in Section 6 , and $H_{o, a v}$ is the monthly average extraterrestrial irradiation. $H_{o}$ is computed for each day and location by the following formula:

$H_{o}=(24 \times 60 / \pi) G_{S C} d_{r}\left[\cos (\varnothing) \cos (\delta) \cos \left(w_{s}\right)+w_{s} \sin (\varnothing) \sin (\delta)\right]$

With

$H_{o} \quad$ the extra-terrestrial radiation $\left(\mathrm{MJ} / \mathrm{m}^{2}\right.$ day)
$G_{s c} \quad$ the solar constant $=1367 \mathrm{~W} / \mathrm{m}^{2}$, as energy of the sun per unit time received on a unit area of the surface perpendicular to the propagation direction of the radiation, at mean earth-sun distance, outside of the atmosphere.

$d_{r} \quad$ the inverse relative distance Earth-Sun, as defined below in Eq. (3)

$w_{s} \quad$ the sunset hour angle, as defined in Eq. (4) [10]

$\delta$ the solar declination angle, as defined by Eq. (5)

$\emptyset \quad$ the latitude of the location (rad)

$n \quad$ the $n$th day of the year $(1-365)$

$d_{r}=1+0.033 \cos (2 \pi n / 365)$

The sunset hour angle, when the incidence angle is $90^{\circ}$, as is needed for CSP plants [33], is defined as:

$\cos \left(w_{s}\right)=-\tan (\varnothing) \tan (\delta)$

The declination angle is defined by the equation of Cooper [34] as:

$\delta=23.45 \sin [2 \pi(284+n) / 365]$

As a result, the daily extra-terrestrial irradiation can be expressed by Eq. (6)

$H_{0}=(24 \times 60 / \pi) G_{S C} d_{r}\left[\cos (\varnothing) \cos (\delta) \cos \left(w_{s}\right)+w_{s} \sin (\varnothing) \sin (\delta)\right]$

Liu and Jordan [4] studied the statistical characteristics of solar irradiation, using the clearness index (a measure of the atmospheric transmittance) as a random variable. They demonstrated that the hourly clearness index was related to the monthly average value. Bendt et al. [5] thereafter proposed a frequency distribution of daily clearness index values, staring from monthly average values. Initially based upon irradiation studies in the USA, this approach has been validated for different worldwide locations [33-36].

The distribution to the frequency of days with a value of the clearness index $K_{T}$ has an exponential correlation throughout the month ranging between the minimum and maximum values recorded.

The correlation is expressed as:

$\mathbf{f}\left(\mathrm{K}_{\mathrm{T}}\right)=\left[\mathrm{e}_{T, \min }^{\gamma K}-\mathrm{e}_{T}^{\gamma K}\right] /\left[\mathrm{e}_{T, \min }^{\gamma K}-\mathrm{e}_{T, \max }^{\gamma \mathrm{K}}\right]$

Where $\gamma$ is a dimensionless parameter that defines the particular exponential distribution, given by:

$\gamma=-1.498+\left[1.184 \xi-27.182 \mathrm{e}^{(-1.5 \xi)}\right] /\left(K_{T, \max }-K_{T, \min }\right)$

Where $\xi$ is also a dimensionless parameter given by:

$\xi=\left(K_{T, \max }-K_{T, \min }\right) /\left(K_{T, \max }-K_{T, a v}\right)$

The minimum and maximum values of $K_{T} K_{T, \max }$ and $K_{T, \min }$ respectively, are given by:

$K_{T, \min }=0.05$

$K_{T, \max }=0.6313+0.267 K_{T, a v}-11.9\left(K_{T, a v}-0.75\right)^{8}$

To obtain a daily clearness index, Knight et al. [7] define daily $K_{T}$ as a function of $n_{d k}$ the day of the month and $n d m$ as the number of days of the month, with $\left(n_{d k}-0.5\right) / n d m=\alpha$ :

$\mathrm{K}_{\mathrm{T}}=(1 / \gamma)\left[\ln \left\{(1-\alpha) \mathrm{e}_{T, \min }^{\gamma K}+\alpha \mathrm{e}_{T, \text { max }}^{\gamma K}\right\}\right]$

Finally, the daily total irradiation, $H$, is obtained following Eqs. (1) and (12), where the daily clearness index is multiplied with daily extra-terrestrial irradiation $H_{0}$.

$H=K_{T} \cdot H_{0}$

In summary, with all mentioned equations solved, artificial months with artificial daily total radiations $(H)$ are created, where months are ordered from the lowest to highest radiation level. 


\subsubsection{Sequence of days}

Daily total radiation data results from Eqs. (1) and (13) are obtained in a predefined sequence through the month by varying radiation levels in an ascending and descending pattern;. However, the sequence of days in which they succeed each other is unknown, and obviously does not strictly follow an ascending or descending order, but rather present a random occurrence sequence.

Knight et al.[7] and Graham et al. [37,38] apply a separate methodology to obtain the 31 clearness indexes which succeed each other in a month (with 31 days) and propose a particular sequence to organize the clearness indexes as shown in Table 6. This technique is currently used to generate typical years in simulation programs such as TRNSYS [23].

\subsubsection{Estimation of the hourly diffuse and beam radiation}

As CSP plants accept only DNI, diffuse irradiation is subtracted from the global irradiation to obtain the beam irradiation, which is the one we are interested. Direct irradiation follows a constant direct direction, whilst diffuse irradiation is the part of the global irradiation that follows different directions due to interactions with the atmosphere (See Fig. 10).

The daily diffuse irradiation $\left(H_{d}\right)$ is defined by the Erbs correlations [39]: the daily total diffuse fraction depends on the sunset hour angle $\left(w_{s}\right)$ and is defined as:

For $w_{s} \leq 81.4^{\circ}$

$$
\begin{array}{cl}
H_{d} / H=1-0.2727 K_{T}+2.4495 K_{T}^{2}-11.951 K_{T}^{3}+9.3879 K_{T}^{4} & \text { if } K_{T}<0.715 \\
=0.143 & \text { if } K_{T} \geq 0.715
\end{array}
$$

For $w_{s} \geq 81.4^{\circ}$

$$
\begin{array}{cc}
H_{d} / H=1+0.2832 K_{T}-2.5557 K_{T}^{2}+0.8448 K_{T}^{3} & \text { if } K_{T}<0.715 \\
=0.175 & \text { if } K_{T} \geq 0.715
\end{array}
$$

With $H$ and $H_{d}$ calculated for each day.

The hourly irradiation $(I)$ is obtained by the ratio of hourly to daily total irradiation $\left(r_{t}\right)$ which is defined by the following equation from Collares-Pereira and Rabl [39] as function of the hour angle ( $w$ in radians) and the sunset hour angle $\left(w_{\mathrm{S}}\right)$ :

$r_{t}=I / H=(\pi / 24)[\mathrm{a}+\mathrm{b} \cos (w)]\left\{\left[\cos (w)-\cos \left(w_{s}\right)\right] /\left[\sin \left(w_{\mathrm{s}}\right)-\pi w_{s} \cos \left(w_{s}\right) / 180\right]\right\}$

With $a$ and $b$ constants given by:

$a=0.409+0.5016 \sin \left(w_{s}-60 \pi / 180\right)$

$b=0.6609-0.4767 \sin \left(w_{s}-60 \pi / 180\right)$

Based on Liu and Jordan [4], assuming that $I_{d} / H_{d}$ is the same as $I_{0} / H_{0}$, where is $I_{0}$ the hourly extra-terrestrial irradiation, the hourly diffuse irradiation $I_{d}$ is obtained as the ratio of hourly diffuse to daily diffuse irradiation $r_{d}$, which is defined as:

$r_{d}=I_{d} / H_{d}=(\pi / 24)\left\{\left[\cos (w)-\cos \left(w_{s}\right)\right] /\left[\sin \left(w_{s}\right)-\pi w_{s} \cos \left(w_{s}\right) / 180\right]\right\}$

Finally, hourly beam irradiation $I_{b}$ is calculated by subtracting $I_{d}$ from $I$.
As a result, hourly global and beam irradiation data for every day of the year (typical year of 365 days) are obtained for each location, which will be used as an input for the heliostat field.

The results of the calculations will be given and discussed in Section 7.

\subsubsection{Shortcut estimates, based on recorded temperatures}

The previous methodology related the radiation flux to the sunshine duration. A considerable amount of information is today available on the relationship between the solar irradiation and other meteorological parameters such as cloud-cover, amount of rain, humidity and/or temperature. The parameter that has the largest measurement network is the ambient temperature, and a shortcut method to relate the extra-terrestrial solar irradiation to the average daily solar irradiation.

These different methods were reviewed by Gajo et al. [40], relating $H$ to $T_{\max }, T_{\min }$ or $T_{\text {mean }}$.

The authors found that the original Hargreaves method performed overall best for different locations.

The Hargreaves method predicts $K_{T}$ as:

$K_{T}=k_{R S}\left(T_{\max }-T_{\min }\right)^{0.5}$

The adjustment coefficient $k_{R S}$ is empirical and differs for 'interior' or 'coastal' regions:

- for 'interior' locations, where land mass dominates and air masses are not strongly influenced by a large water body, $k_{R S} \sim 0.16$;

- for 'coastal' locations, situated on or adjacent to the coast of a large land mass and where air masses are influenced by a nearby water body, $k_{R S} \sim 0.19$.

The temperature difference method is recommended for locations where it is not appropriate to import radiation data from a regional station, either because homogeneous climate conditions

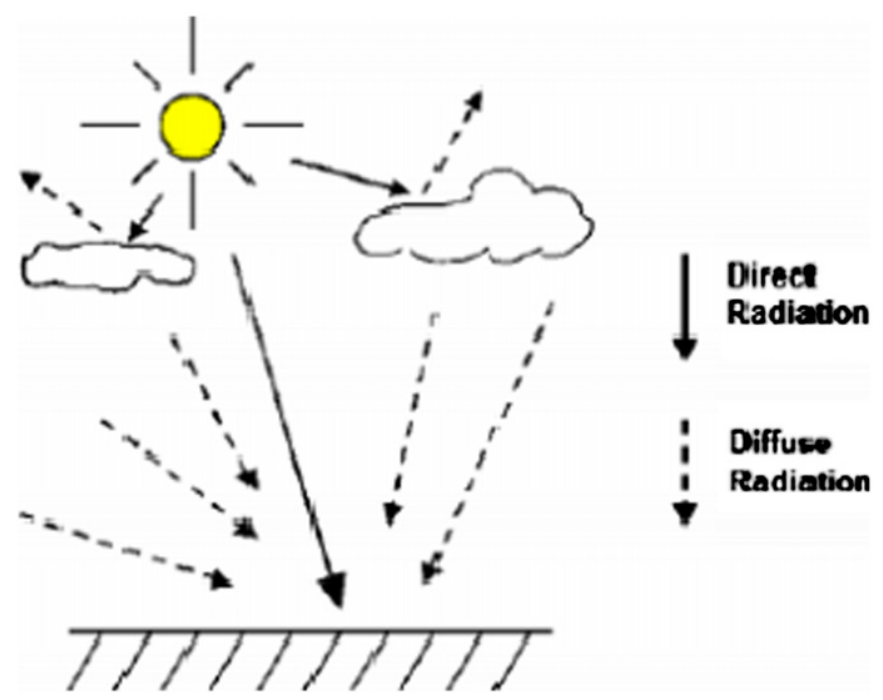

Fig. 10. Direct and diffuse irradiation.

Table 6

Sequence model of the daily clearness indexes.

\begin{tabular}{ll}
\hline Mean clearness index $\left(\boldsymbol{K}_{\boldsymbol{T}, a v}\right)$ & Sequence of days through the month \\
\hline $\boldsymbol{K}_{\boldsymbol{T}, \boldsymbol{a v}}<=\mathbf{0 . 4 5}$ & $24-28-11-19-18-3-2-4-9-20-14-23-8-16-21-26-15-10-22-17-5-1-6-29-12-7-31-30-27-13-25$ \\
$\mathbf{0 . 4 5}<\boldsymbol{K}_{\boldsymbol{T}, \boldsymbol{a v}}<=\mathbf{0 . 5 5}$ & $24-27-11-19-18-3-2-4-9-20-14-23-8-16-21-7-22-10-28-6-5-1-26-29-12-17-31-30-15-13-25$ \\
$\boldsymbol{K}_{\boldsymbol{T}, \boldsymbol{a v}}>\mathbf{0 . 5 5}$ & $24-27-11-4-18-3-2-19-9-25-14-23-8-16-21-26-22-10-15-17-5-1-6-29-12-7-31-20-28-13-30$ \\
\hline
\end{tabular}


Table 7

Selected locations with basic data.

\begin{tabular}{|c|c|c|c|c|c|c|c|c|}
\hline \multirow[t]{2}{*}{ Location } & \multirow{2}{*}{$\begin{array}{l}\text { Latitude } \\
\text { (rad) }\end{array}$} & \multirow{2}{*}{$\begin{array}{l}\text { Longitude } \\
\text { (rad) }\end{array}$} & \multirow{2}{*}{ 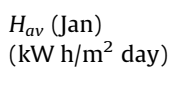 } & \multirow{2}{*}{ 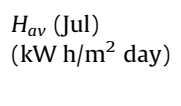 } & \multicolumn{2}{|l|}{ Jan } & \multicolumn{2}{|l|}{ Jul } \\
\hline & & & & & $T_{\max }\left({ }^{\circ} \mathrm{C}\right)$ & $T_{\min }\left({ }^{\circ} \mathrm{C}\right)$ & $T_{\max }\left({ }^{\circ} \mathrm{C}\right)$ & $T_{\min }\left({ }^{\circ} \mathrm{C}\right)$ \\
\hline Chuquicamata, Chile & -22.5 & -68.9 & 8.32 & 4.99 & 25.2 & 5.8 & 21.1 & 1.5 \\
\hline Upington, RSA & -28.5 & 21.08 & 7.93 & 3.89 & 36.7 & 20.5 & 21.5 & 1.5 \\
\hline Geraldton, Australia & -28.78 & 114.61 & 8.28 & 3.41 & 33.6 & 19.3 & 19.7 & 9.1 \\
\hline Sevilla, Spain & 37.41 & -5.98 & 2.56 & 7.80 & 15.9 & 7.6 & 35.7 & 19.9 \\
\hline Font Romeu, France & 42.5 & 2.03 & 1.81 & 6.17 & $9.5^{\mathrm{a}}$ & $0.1^{\mathrm{a}}$ & $26.9^{\mathrm{a}}$ & $14.2^{\mathrm{a}}$ \\
\hline Marrakech, Morocco & 31.6 & -8 & 3.49 & 7.26 & 21.4 & 6.6 & 37.3 & 19.8 \\
\hline Sainshand, Mongolia & 44.89 & 110.14 & 2.21 & 6.11 & $-18.5^{\mathrm{b}}$ & $-34.7^{\mathrm{b}}$ & $23.5^{\mathrm{b}}$ & $9.4^{\mathrm{b}}$ \\
\hline Ely, USA & 39.3 & -114.85 & 2.56 & 7.38 & 3.3 & -13 & 31.3 & 9.7 \\
\hline
\end{tabular}

a Data taken from nearby Albi.

${ }^{\mathrm{b}}$ Data taken from nearby Ulan Bator.

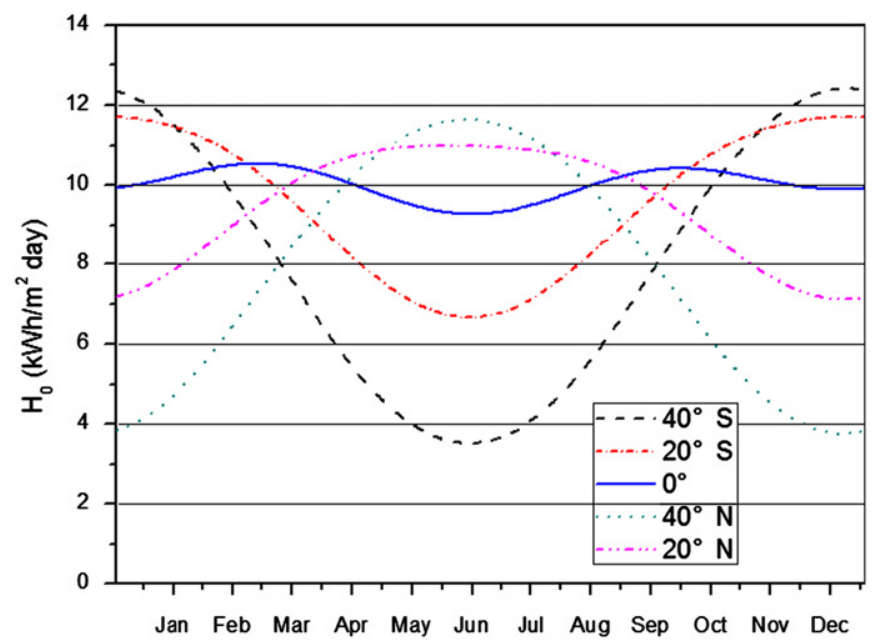

Fig. 11. Calculated values of $H_{0}$.

do not occur, or because data for the region are lacking. For island conditions, the methodology of Eq. (20) is not appropriate due to moderating effects of the surrounding water body.

Since $T_{\max }$ and $T_{\min }$ data are indeed widely available, the Hargreaves $K_{T}$-values can be used in the methodology of Section 5.1 , and results of the both methods will be illustrated in Section 7.

\section{Model parameters}

\subsection{Common measurement methods of solar radiation}

Solar radiation can be measured with pyranometers, radiometers or solarimeters. The instruments contain a sensor installed on a horizontal surface that measures the intensity of the total solar radiation, i.e., both direct and diffuse radiation from cloudy conditions. The sensor is often protected and kept in a dry atmosphere by a glass dome that should be regularly wiped clean. Where pyranometers are not available, solar radiation is usually estimated from the duration of bright sunshine. The actual duration of sunshine, $\mathrm{n}$, is measured with a CampbellStokes sunshine recorder. This instrument records periods of bright sunshine by using a glass globe that acts as a lens. The sun rays are concentrated at a focal point that burns a hole in a specially treated card mounted concentrically with the sphere. The movement of the sun changes the focal point throughout the day and a trace is drawn on the card. If the sun is obscured, the

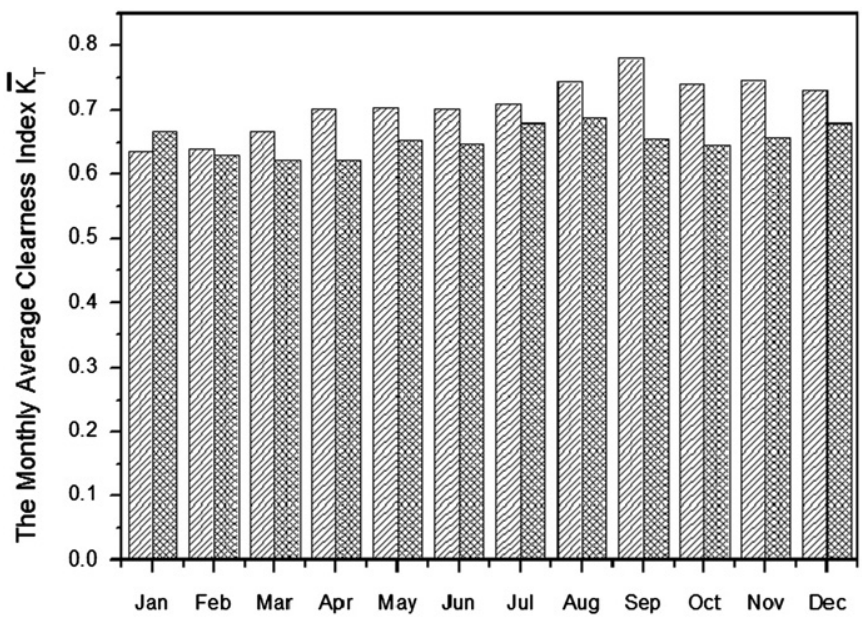

Fig. 12. Calculated average monthly clearness index 2 WII by the model [Eq. (1)] and by the Hargreaves method [Eq. (21)] at Upington (RSA).

trace is interrupted. The hours of bright sunshine are indicated by the lengths of the line segments.

\subsection{Available information}

There are two reliable sources that provide information on the two of the most basic meteorological parameters: monthly mean temperature and solar radiation. These sources are the NASA website [41] and TUTIEMPO [42]. NASA has produced a grid map of the longitude. The solar radiation data are an estimate that has been produced from satellite-based scans of terrestrial cloudcover. Note that NASA does not provide the mean-daily maximum and minimum temperature. TUTIEMPO on the other hand provides daily mean, maximum and minimum temperature data for any given location. The data are based on measurements carried out by a wide network of meteorological stations and hence these latter data are very reliable. Note that the NASA data are available on a mean-monthly basis, whereas TUTIEMPO are downloadable on a day-by-day basis. It is important to remember that NASA data are based on satellite observations that represent inferred values of irradiation; in contrast, TUTIEMPO provides groundmeasured data for temperature. Hence, if reliable regressions are available between irradiation and mean temperature, then the latter data may be used to obtain more realistic estimates of irradiation. 

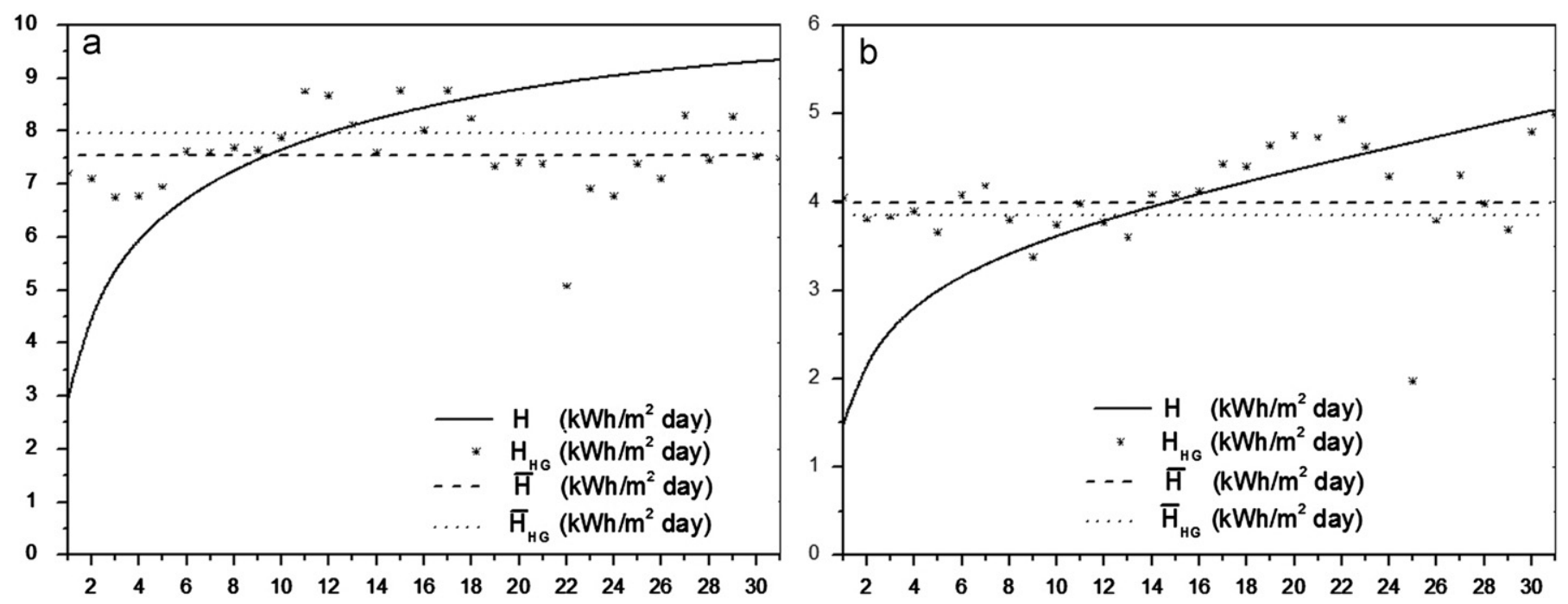

Fig. 13. The total daily radiation for Upington in (a), January (summer) and (b), July (winter).

\subsection{Selected locations}

To illustrate the use of the methodology of Sections 5,8 locations were selected because of being already associated with CSP, or announced as potential sites for STP. The essential data of the locations are given is Table 7 .

\section{Results and discussion}

\subsection{Calculations of $H_{0}, H$ and $H_{b}$}

Having developed the underlying equations of the calculation method in Section 5, and using the data acquisition of Section 6, the present section will illustrate the use of the data obtained.

The monthly extra-terrestrial irradiation, $H_{0}$, computed by Eq. (6), is illustrated in Fig. 11 for different latitudes in both hemispheres and shows the seasonal dependence, whilst also illustrating the maximum and minimum values obtained throughout the year.

To proceed with the calculation of the monthly average clearness index, $K_{T, a v}$ Eq. (1) is used together with NASA-data [41]. Results are illustrated as example in Fig. 12 for the Upington location. The Figure also includes the results obtained from the Hargreaves method [Eq. (21)] using TUTIEMPO-data [42]. Clearly, both methods provide similar results of $K_{T, a v}$ for most of the months, however with higher Hargreaves-values in Spring and Autumn. The model approach thus provides slightly more conservative $K_{T, a v}$ values, and is recommended for design.

The daily total irradiation is thereafter obtained by applying the daily clearness index, $K_{T}$, and the daily extra-terrestrial irradiation $H_{0}$. Fig. 13 shows the model-predicted total daily irradiation, ordered in ascending daily pattern for Upington, for a summer month (January) and a winter month (July). The monthly average $H$, calculated by Eq. (13) in January and July, is $7.92 \mathrm{~kW} \mathrm{~h} / \mathrm{m}^{2}$-day and $3.92 \mathrm{kWh} / \mathrm{m}^{2}$-day, respectively. Similar evolutions can be obtained for the other selected locations. Applying the Knight et al. [7] sequence model for the daily clearness indexes, as function of $K_{T, a v}$ transforms the ascending nature of the consecutive days into a wave-function, although monthly average values of $H$ remain unchanged.

A similar evolution can be predicted using daily $K_{T}$-values resulting from the daily $T_{\max }$ and $T_{\min }$ data, according to Eq. (21).

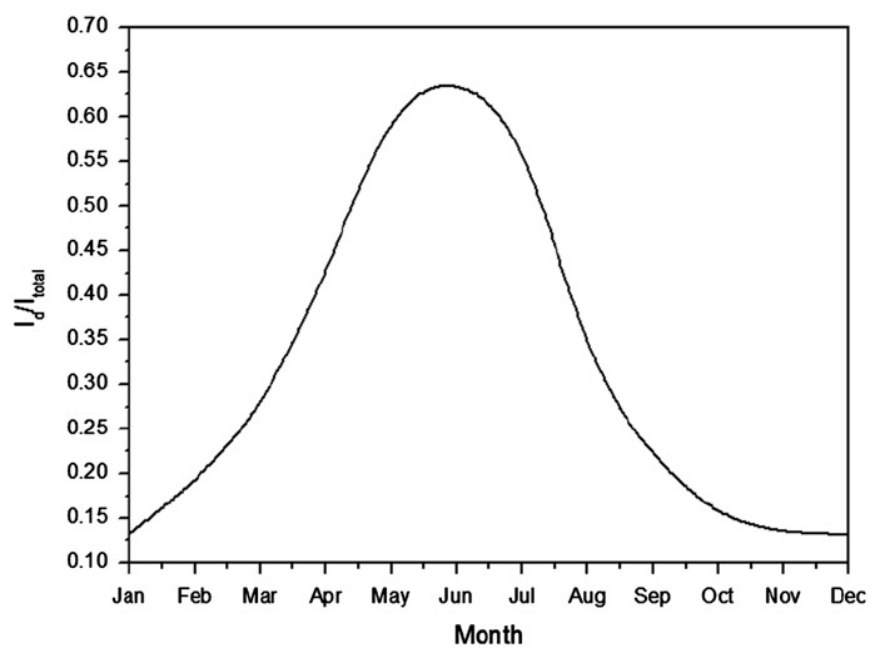

Fig. 14. The monthly average $I_{d} / I$ ratio for Chuquicamata (Chile).

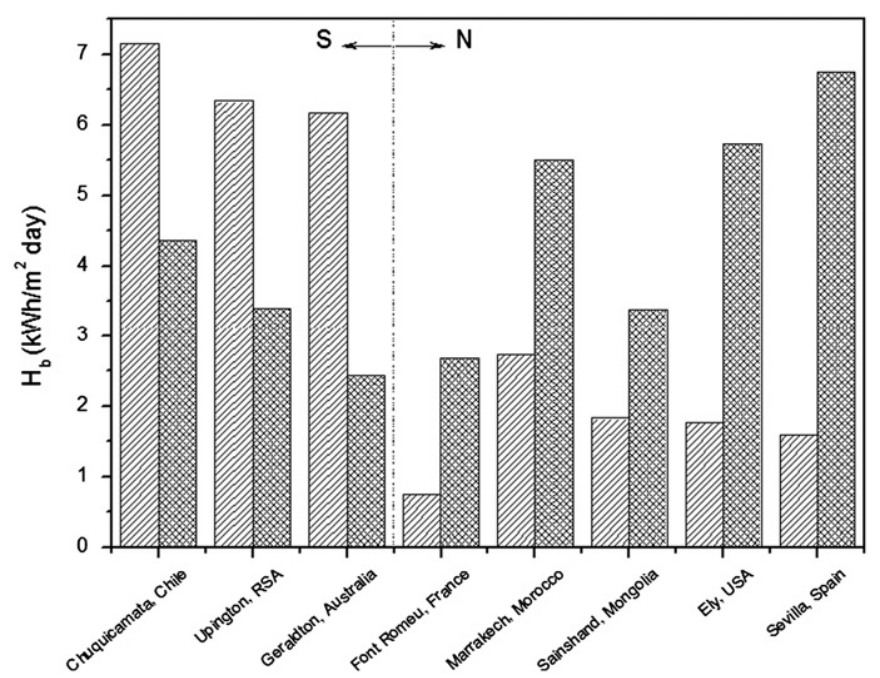

Fig. 15. The daily solar beam irradiation, $H_{b}$, on the 15 th of January the 15 th of July for different locations in both the Southern and Northern Hemisphere. 
These results are also shown in Fig. 13. Clearly, the Hargreaves approach provides a more constant $H$-value throughout the month since not respecting an ascending daily pattern. The monthly average value of $H\left(H_{R G}\right)$ is closely related to the model predictions: $7.56 \mathrm{~kW} \mathrm{~h} / \mathrm{m}^{2}$-day in January, and $4.07 \mathrm{~kW} \mathrm{~h} / \mathrm{m}^{2}$-day in July, i.e., a deviation of $4.5 \%$ and $3.8 \%$ only with the pre-cited values of the model-predicted average values.

The most important result towards CSP design requires the direct (beam) irradiation, obtained by withdrawing the diffuse irradiation, $H_{d}$, from the total irradiation, $H$, according to Eqs. (14) and (15).

The ratio of the diffuse to total irradiation is illustrated for Chuquicamata in Fig. 14: the more cloudy winter season (AprilAugust) is reflected in the higher value of the ratio.

The resulting beam radiation, $H_{b}$, for representative days in Summer and winter, for all locations, is shown in Fig. 15, whereas a more detailed monthly average evolution for some locations, is shown in Fig. 16.

Finally, a complete hourly evolution can be predicted by the model, as illustrated in Fig. 17, where the radiation flux can be seen to increase from sunrise to noon, and thereafter decreasing again till sunset.

It is also clear that the selection of the CSP nominal capacity will be a compromise between the seasons, accounting for the capability of thermal storage, and the use of a backup system.

\subsection{Methodology to apply the predictions in CSP design}

Having established the annual, monthly and daily levels of direct (beam) solar irradiation, its impact on the power yield of the CSP can be assessed. To do so, it should be remembered that each of the operations of the overall CSP-layout has its own efficiency, reflected in its overall efficiency. The projected overall efficiency of CSP plants was assessed by S\&L and SNL, as presented in Table 8, including projected increased efficiencies as a result of present and future improvements.

The efficiencies of the essential components has been reported by S\&L, and represented in Table 9 .

Considering that about $10 \%$ of the generated electricity will be used internally for the plant utilities (mostly pumping), 90\% of the combined efficiencies do indeed vary between 14 and $18 \%$.

The final CSP performance simulation follows the strategy of Fig. 18, with a specific algorithm to be used, in terms of DNI, TES and BS, as previously presented in Fig. 9.

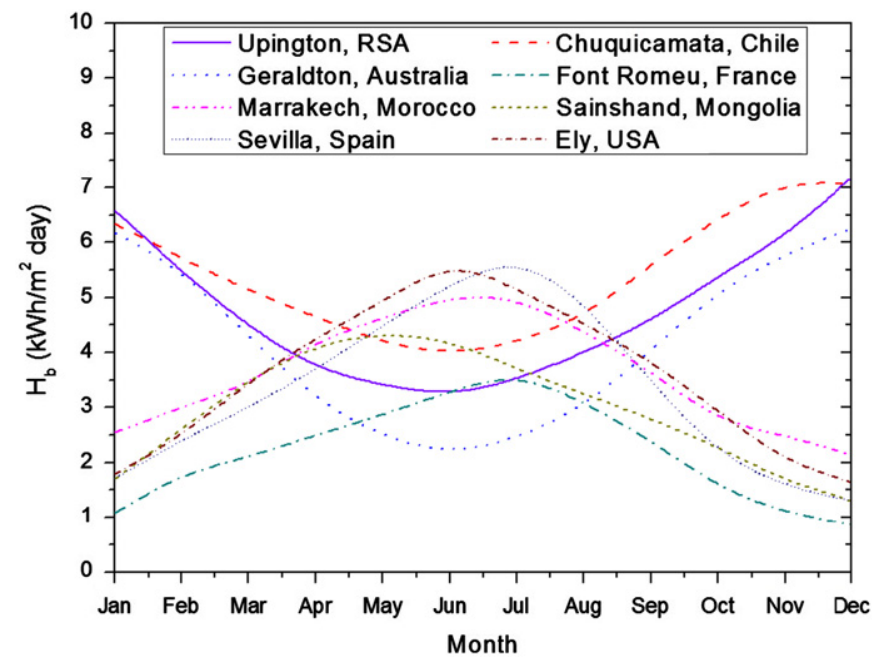

Fig. 16. Evolution of the average monthly direct (beam) irradiation in 8 locations.

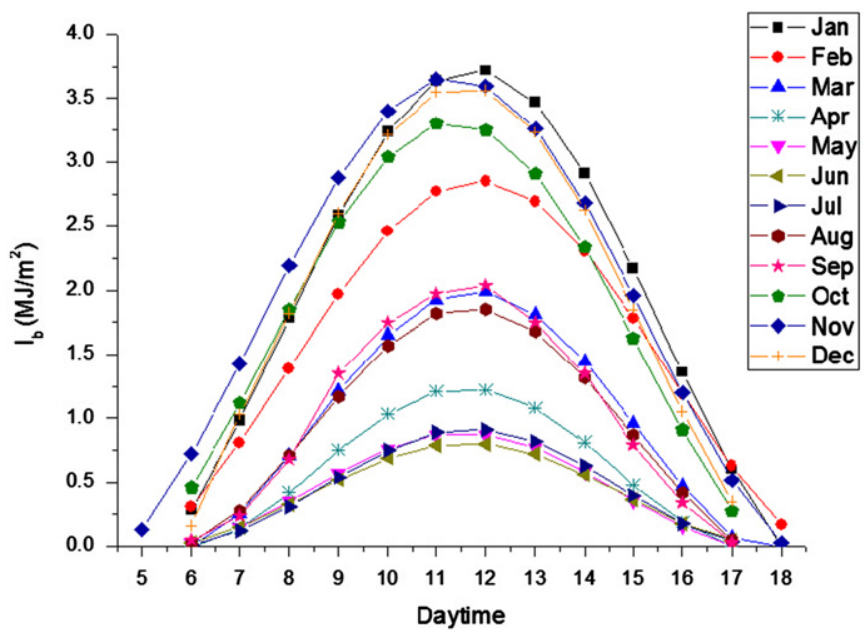

Fig. 17. Hourly evolution at the 15 th of the respective months, in Chuquicamata (Chile).

Table 8

Projected overall CSP efficiency.

\begin{tabular}{lllllll}
\hline Year of projection & 2004 & 2004 & 2008 & 2008 & 2020 & 2020 \\
\hline $\begin{array}{l}\text { Annual overall CSP efficiency (\%) } \\
\text { Source of estimation }\end{array}$ & $\begin{array}{l}13.0 \\
\text { S\&L }\end{array}$ & $\begin{array}{l}13.7 \\
\text { SNL }\end{array}$ & $\begin{array}{l}16.1 \\
\text { S\&L }\end{array}$ & $\begin{array}{l}16.6 \\
\text { SNL }\end{array}$ & $\begin{array}{l}17.3 \\
\text { S\&L }\end{array}$ & $\begin{array}{l}18.1 \\
\text { SNL }\end{array}$ \\
\hline
\end{tabular}

Table 9

Values of CSP-component efficiencies.

\begin{tabular}{ll}
\hline Component & Efficiency (\%) \\
\hline Solar field & $48-50$ \\
TES & $>99$ \\
Power block & $\sim 40$ \\
\hline
\end{tabular}

- DNI is calculated on hourly bases

- The total energy flux reflected by the heliostat field is calculated

- The expected nominal capacity of the plant is selected

- 21 consecutive days of lowest radiation levels are selected to coincide with the maintenance period, thus limiting losses during plant stand-still

- From a given starting day of the year, e.g., January 1st., at 6:00 a.m., and repeated for all hours of the year, the following different options need to be assessed:

- If the solar thermal flux exceeds the required value to operate the plant at nominal capacity, only solar thermal energy will be used, whilst excess solar energy is stored in the HTF hot storage tank. The BS-system is not used, and additional excess solar thermal energy cannot be used;

- If the solar thermal flux is insufficient to meet the nominal capacity, but enough thermal energy is stored in the hot tank, no BS is needed, and the plant will operate on combined solar radiation and stored energy;

- If the combined solar thermal flux and energy stored are insufficient, the plant needs to operate in its hybrid configuration, using the BS to meet the thermal requirements.

The detailed simulations are extensive, and are not included in the present paper. They will be reported upon in a follow-up 


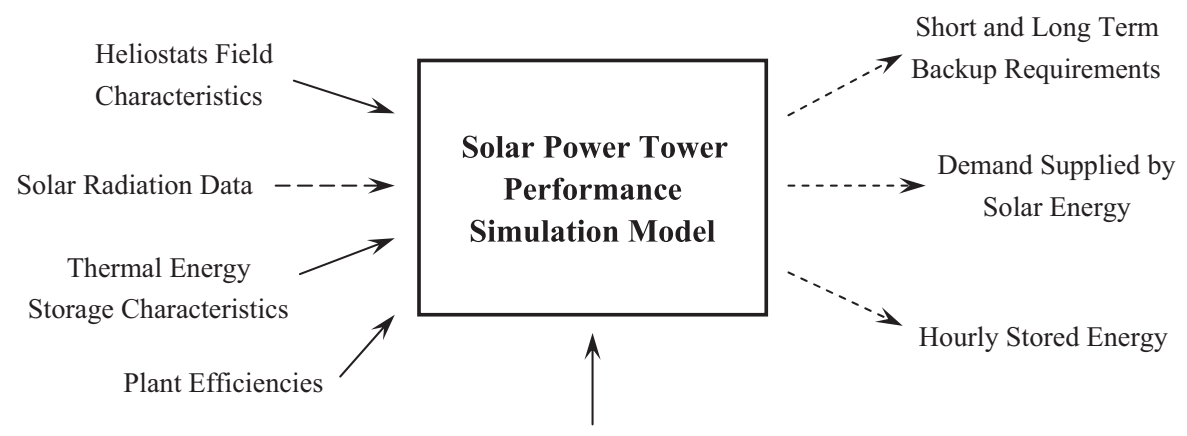

Plant Restrictions

Fig. 18. Performance simulation method.

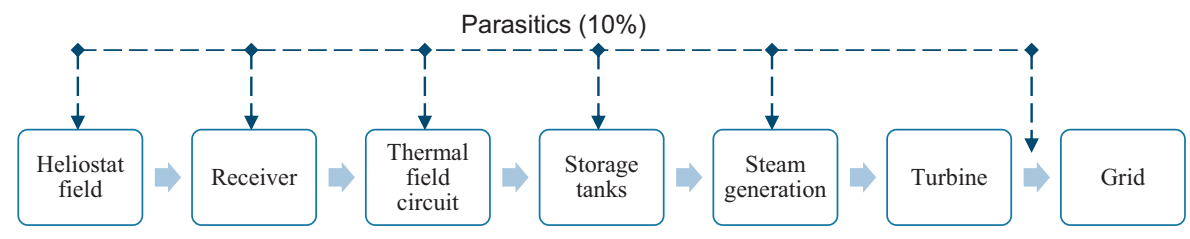

Fig. 19. Sequence of the components of the SPT.

paper, considering the application of the solar tower collector, with molten salt HTF/TES, and with natural gas-fired BS. The turbine capacity will be $19.9 \mathrm{MW}_{\mathrm{el}}$, chosen because of the extensive data available for the Gemasolar plant (Spain). Such simulations will be carried out for those locations where the annual average daily irradiation flux exceeds $\sim 4 \mathrm{~kW} \mathrm{~h} / \mathrm{m}^{2}$-day.

Due to parasitics (electricity use within the plant for pumps, cooling towers, compressors, instrumentation and controls, lighting, heat tracing..), estimated at $10 \%$ for a Gemasolar-type hybrid application, the net output to the grid will be $17.9 \mathrm{MW}_{\mathrm{el}}$ during the period of operation. The annual power yield of the hybrid Gemasolar plant is $110 \mathrm{GWh}$ h/year [2]. The specific energy production, i.e., the ratio of total annual grid energy and the rated net power output of the plant is therefore $110,000 / 17.9=6145$ h/year. For total of $8760 \mathrm{~h} /$ year, the overall yield is $70.1 \%$, assumed realistic in view of the annual maintenance period (zero production), short duration disturbances, and very low solar irradiation in winter. As will be shown hereafter for the Chiquicamata example, $69.5 \mathrm{GW} \mathrm{h} /$ year will be generated from the solar energy alone (the remaining turbine power being generated by the back-up natural gas system). The average net solar yield thus represents 69,500/17.9=3882 h/ year, or $44.3 \%$ (for the $8760 \mathrm{~h}$ annual operation).

For the simulations, it is considered that the plant works with a thermodynamic cycle in a steady state.

If a total energy production needed from the turbine is 19.9 $\mathrm{MW}_{\mathrm{el}}$, the efficiencies of the different CSP components will determine the hourly heat flow along the system, from heliostats to turbine and grid. The system flow sheet is illustrated in Fig. 19, and the additional required information for each step of the sequence is given below in different notes.

The total energy of $19.9 \mathrm{MW}_{\mathrm{el}}$ in the steam turbine must be reached each hour, with part of this energy added to the molten salts in the receiver (reflected by the heliostat field), and the rest of the energy added by the storage system, and/or by the back-up system (when receiver and storage energies are insufficient) according to Fig. 9 and the strategy of Fig. 18. By simulating the plant performance at the heliostat and receiver levels, the additional energy required by the storage system and the backup system can be determined. Molten salt properties at each point of the thermodynamic cycle are fixed and known

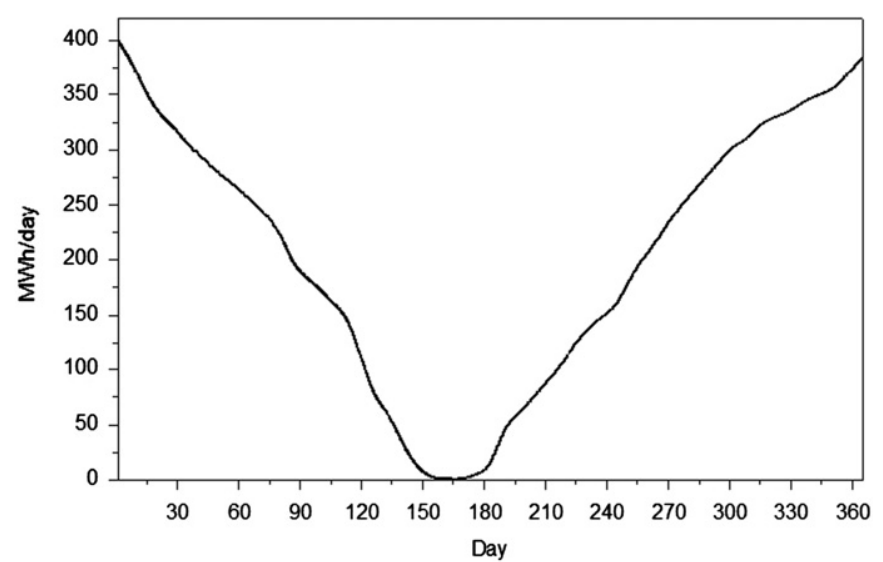

Fig. 20. Electricity generation through the year in a Chuquicamata SPT, only with solar resource configuration.

\section{Note 1. Heliostat field}

Since the heliostats follow the sun by a two-axis tracking, no correction for the incident angle $\theta$ must be made $(\cos \theta=1)$, and $I_{b}$ corresponds to the real hourly irradiation at the heliostat field.

First, the energy reflected by the heliostat field must be calculated each hour, where hourly radiation data is extracted from the calculations of Sections 5 and 6 before. The total energy reflected by the heliostat field and concentrated in the receiver is then determined by the heliostat field efficiency and the heliostat field reflective surface area. The heliostat field efficiency $\left(\eta_{\mathrm{HF}}\right)$ is mostly characterized by its reflectivity, optical efficiency, heliostat corrosion avoidance and cleanliness. A value of 48 to $50 \%$ is commonly used (Table 9).

\section{Note 2. Receiver}

The reflected energy is concentrated in the receiver, which acts as a heat exchanger where circulating molten salts absorbs solar energy. Total energy absorbed by molten salts is determined by the receiver efficiency, where receiver thermal losses are primarily driven by the thermal emissivity of the receiver panels 


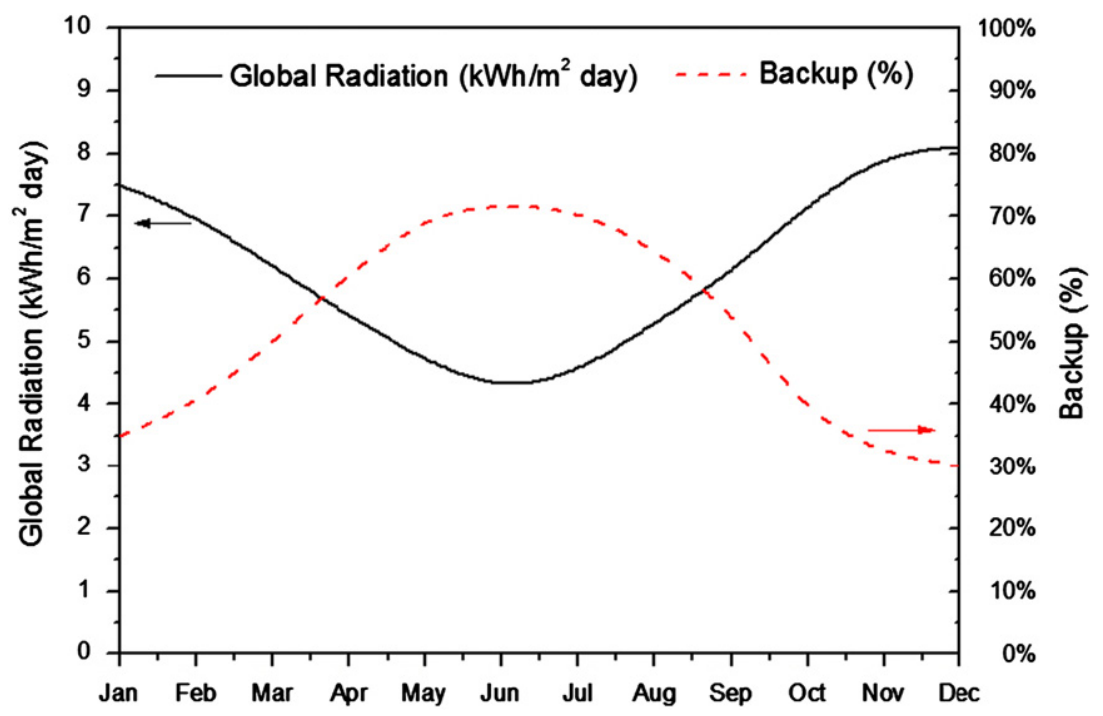

Fig. 21. Monthly backup requirements in the Chuquicamata SPT, in hybrid operating mode.

(radiation losses) and by the receiver temperature. Commonly, radiation losses are “ $\ll 1 \%[14]$.

\section{Note 3. THF Circuit and THF storage}

Piping and tank losses are very limited, due to the efficient isolation applied, normally again $<1 \%$ [14].

Note 4. Steam generation and reheated Rankine cycle

The efficiencies to be considered include the design point turbine cycle efficiency; start-up losses; partial load operation, and steam generation system efficiency. Losses due to minimum turbine load requirements do not apply since the plant has a thermal storage and back-up system. Commonly, a value of $40 \%$ is assigned to the overall efficiency of the thermal power block of the plant (Table 9).

Note 5. Parasitics (in-plant energy use)

The parasitic consumption considers internal electricity usage mostly in heliostat tracking, THF pumps, condensate pumps, feedwater pumps, cooling water pumps, cooling tower fans and electrical heat tracing system, but additionally in instrumentation, controls, computers, valve actuators, air compressors, and lighting. A maximum 10\% [13] was measured by Sargent and Lundy Consulting Group

Considering component efficiencies, a simple estimation of solar to electricity efficiency $\left(\eta_{\text {solar }}\right)$ of the plant can be obtained by using component efficiencies to calculate the total efficiency of energy transformation.

$\eta_{\text {solar }}=\eta_{H F} \times \eta_{\text {rec }} \times \eta_{\text {piping }} \times \eta_{\text {storage }} \times \eta_{\text {cycle }} \times\left(1-\eta_{\text {parasitic }}\right) \times A$

Where,

$\eta_{H F}$ : Heliostat field efficiency,

$\eta_{\text {rec}}$ : Receiver efficiency,

$\eta_{\text {piping: }}$ Piping efficiency,

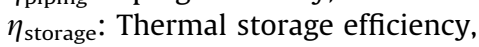

$\eta_{\text {cycle: }}$ Power block gross efficiency,

$\eta_{\text {parasitic: }}$ Parasitics,

$A=$ Plant availability (capacity factor).

Initial results of the simulation for the Chuquicamata initiative, reveal that the solar generation will account for
$69.5 \mathrm{GW}$ h/year, in the case of a conservative $13 \%$ overall efficiency.

Figs. 20 and 21 provide some indications of the simulated results. The zero production between days $\sim 150$ and 180 correspond with the supposed annual shut-down period for overall maintenance.

Provided overall efficiencies will increase over the coming years, due to technical improvements, the solar energy contribution will increase, thus reducing the required backup, as will be discussed in a follow-up paper, considering the overall design of the SPT plant.

\section{Conclusions}

To determine the optimum design and operation of the CSP throughout the year, whilst defining the required TES and/or BS, an accurate estimation of the direct daily solar irradiation is needed

The paper develops the underlying equations to calculate the monthly extra-terrestrial irradiation, $H_{0}$,

the monthly average clearness index, $K_{T, a v}$ the daily total irradiation, and the direct (beam) irradiation.

Results of the model approach is given for 8 selected locations, in both Northern and Southern hemisphere.

Having established the annual, monthly and daily levels of direct (beam) solar irradiation, its impact on the power yield of the CSP can be assessed. The projected overall efficiency of CSP plants was assessed and included in a CSP performance simulation, according to a proposed strategy. Initial simulation results are illustrated for a $19.9 \mathrm{MW}_{\mathrm{el}}$ Solar Power Tower project, with molten salts as HTF, and operating in an hybrid way (including heat storage and back up fuel). In the assesses example, solar generation will account for $69.5 \mathrm{GWh}$ /year, in the case of a conservative $13 \%$ overall efficiency. Provided overall efficiencies will increase over the coming years, due to technical improvements, the solar energy contribution will increase, thus reducing the required backup, as will be discussed in a follow-up paper, considering the overall design of the SPT plant.

\section{References}

[1] 〈http://www.alternative-energy-resources.net/solarenergydisadvantages. html $\rangle$. 
[2]〈http://www.torresolenergy.com/TORRESOL/gemasolar-plant/en 〉.

[3] Duffie J, Beckmann W. Solar engineering of thermal processes. 3rd ed.. USA: John Wiley and Sons; 2006.

[4] Liu BYH, Jordan RC. The interrelationship and characteristic distribution of direct, diffuse and total solar radiation. Solar Energy 1960;4:1-19.

[5] Bendt P, Collares-Pereira M, Rabl A. The frequency distribution of daily insolation values. Solar Energy 1981;27:1-5.

[6] Stuart R, Hollands K. A probability density function for the beam transmittance. Solar Energy 1988;40:463-7.

[7] Knight K, Klein K, Duffie J. A methodology for the synthesis of hourly weather data. Solar Energy 1991;46:109-20.

[8] OECD/IEA, technology roadmap, concentrating solar power, 2010.

[9] Müller-Steinhagen $\mathrm{H}$, Trieb F. Concentrating solar power: a review of the technology. Ingenia 2004;18:43-50.

[10] Llorente I, Álvarez JL, Blanco D. Performance model for parabolic trough solar thermal power with thermal storage: comparison to operating plant data. Solar Energy 2011;85:2443-60.

[11] Barlev D, Vidu R, Stroeve P. Innovation in concentrated solar power. Solar Energy Materials \& Solar Cells 2011;95(10):2703-25.

[12] SolarPACES, annual Reports, 2006, 2007, 2008, 2009, 2010. Downloadable from: 〈http://www.solarpaces.org/Library/AnnualReports/annualreports. htm $>$.

[13] Sargent and Lundy Consulting Group, assessment of parabolic trough and power tower solar technology cost and performance forecasts, National Renewable Energy Laboratory, 2003.

[14] Ortega J, Burgaleta J, Téllex F. Central receiver system solar power plant using molten salt as heat transfer fluid, May 2008

[15] Pitz-Paal R, Dersch J, Milow B, Téllez F, Ferriere A, Langnickel U., et al. Development steps for concentrating solar power technologies with maximum impact on cost reduction, 2005. Available at: 〈http://pre.ethz.ch/ publications/journals/full/j138.pdf $>$.

[16] Pitz-Paal R, Dersch J, Milow B, Romero M, Téllez F, Ferriere A., et al. European Concentrated Solar Thermal Road-Mapping-Executive Summary, CEECOSTAR Contract: SES6-CT-2003-502578. (2005) 144.

[17] Stine W, Geyer M. Power from the Sun, 2001, 〈http://www.powerfromthe sun.net/book.html >.

[18] Abengoa solar website. 〈http://www.abengoa.es $\rangle$.

[19] N.R.E.L. Website, with the collaboration of SolarPaces, 〈http://www.nrel.gov/ $\operatorname{csp} /$ solarpaces $/\rangle$.

[20] 〈www.guardian.co.uk/environment/2010/oct25/ south-africa-solar-power-plant $\rangle$.

[21] Fernandes D, Pitié F, Cáceres G, Baeyens J. Thermal energy storageHow previous findings determine current research priorities. Energy 2012;39(1): 246-57.

[22] Klein SA, Beckman WA. TRNSYS V14.2 (1996). A transient system simulation tool.

[23] Petrakis M, Kambezidis HD, Lykoudis S, Adamopoulos AD, Kassomenos P, Michaelides IM, et al. Generation of a typical meteorological year for Nicosia Cyprus. Renewable Energy 1998;13(3):381-8.
[24] Pissimanis D, Karras G, Notaridou V, Gavra K. The generation of a typical meteorological year for the city of Athens. Solar Energy 2000;40:405-11.

[25] Aguiar RJ, Collares-Pereira M, Conde JP. Simple procedure for generating sequences of daily radiation values using a library of Markov transition matrices. Solar Energy 1988;40:269-79.

[26] Aguiar RJ, Collares-Pereira MTAG. a time-dependent, autoregressive, Gaussian model for generating synthetic hourly radiation. Solar Energy 1992;46:167-74.

[27] Amato U, Andretta A, Bartoli B, Coluzzi B, Cuomo V. Markow Processes and Fourier analysis as a tool to describe and simulate daily solar irradiance. Solar Energy 1986;37:179-94.

[28] Graham VA, Hollands KGT, Unny TE. A time series model for K, with application to global synthetic weather generation. Solar Energy 1988;40: 83-92.

[29] Graham VA, Hollands KGT. A method to generate synthetic hourly solar radiation globally. Solar Energy 1990;44:333-41.

[30] Gordon JM, Reddy TA. Time series analysis of daily horizontal solar radiation. Solar Energy 1988:41:215-26.

[31] Mora-López LL, Sodracj de Cardona M. Characterization and simulation of hourly exposure series of global radiation. Solar Energy 1997;60:257-70.

[32] Mora-López LL, Sodracj de Cardona M. Multiplicative ARMA models to generate hourly series of global irradiation. Solar Energy 1998;63:283-91.

[33] Tham Y, Muneer T, Davison B. Estimation of hourly averaged solar irradiation: evaluation of models. Building Services Engineering Research and Technology 2010;31(1):9-25.

[34] Muneer T, Fairooz F. Quality control of solar radiation and sunshine measurements-lessons learnt from processing worldwide database. Building Services Engineering Research and Technology 2002;23(3):151-66.

[35] Hawas MM, Muneer T. Study of diffuse and global radiation characteristics in India. Energy Conversion and Management 1984;24(2):143-9.

[36] Badescu V, Gueymard CA, Cheval S, Oprea C, Baciu M, Dumitrescu A, et al. Computing global and diffuse solar hourly irradiation on clear sky. Review and testing of 54 models. Renewable and Sustainable Energy Reviews 2012:16:1636-56.

[37] Graham VA, Hollands KGT, Unny T. A time series model for Kt with application to global synthetic weather generation. Solar Energy 1988;40(2): 83-92.

[38] Graham VA, KGT. Hollands. A method to generate synthetic hourly solar radiation globally. Solar Energy 1990;44(6):333-41.

[39] Tham Y, Muneer T, Davidson B. Estimation of hourly averaged solar irradiation: evluation of models. Building Service Engineering Research and Technology 2010;31(1):9-25.

[40] Gajo EJ, Etxebarria S, Tham Y, Aldali Y, Muneer T. Inter-relationship between mean-daily irradiation and temperature, and decomposition models for hourly irradiation and temperature. International Journal of Low-carbon Technologies 2011;6:22-37.

[41]〈http://eosweb.larc.nasa.gov/cgi-bin/sse/retscreen.cgi?email=rets@nrcan.gc.ca 〉.

[42] 〈http://www.tutiempo.net/en/〉. 